\title{
Coupling the Structural and Functional Assembly of Synaptic Release Sites
}

\author{
Tina Ghelani* and Stephan J. Sigrist ${ }^{1,2 *}$ \\ ${ }^{1}$ Faculty of Biology, Chemistry, Pharmacy, Freie Universität Berlin, Berlin, Germany, ${ }^{2}$ NeuroCure Cluster of Excellence, \\ Charité Universitätsmedizin Berlin, Berlin, Germany
}

Information processing in our brains depends on the exact timing of calcium $\left(\mathrm{Ca}^{2+}\right)$ activated exocytosis of synaptic vesicles (SVs) from unique release sites embedded within the presynaptic active zones (AZs). While AZ scaffolding proteins obviously provide an efficient environment for release site function, the molecular design creating such release sites had remained unknown for a long time. Recent advances in visualizing the ultrastructure and topology of presynaptic protein architectures have started to elucidate how scaffold proteins establish "nanodomains" that connect voltage-gated $\mathrm{Ca}^{2+}$ channels (VGCCs) physically and functionally with release-ready SVs. Scaffold proteins here seem to operate as "molecular rulers or spacers," regulating SV-VGCC physical distances within tens of nanometers and, thus, influence the probability and plasticity of SV release. A number of recent studies at Drosophila and mammalian

OPEN ACCESS

Edited by:

George Augustine,

Nanyang Technological University,

Singapore

Reviewed by:

Lu-Yang Wang,

University of Toronto, Canada

Nadine Ehmann,

Leipzig University, Germany

*Correspondence:

Tina Ghelani

tina.ghelani@fu-berlin.de

Stephan J. Sigrist

stephan.sigrist@fu-berlin.de

Received: 12 June 2018

Accepted: 18 September 2018

Published: 16 October 2018

Citation:

Ghelani T and Sigrist SJ (2018)

Coupling the Structural

and Functional Assembly of Synaptic

Release Sites.

Front. Neuroanat. 12:81.

doi: 10.3389/fnana.2018.00081 synapses show that the stable positioning of discrete clusters of obligate release factor (M)Unc13 defines the position of SV release sites, and the differential expression of (M)Unc13 isoforms at synapses can regulate SV-VGCC coupling. We here review the organization of matured AZ scaffolds concerning their intrinsic organization and role for release site formation. Moreover, we also discuss insights into the developmental sequence of AZ assembly, which often entails a tightening between VGCCs and SV release sites. The findings discussed here are retrieved from vertebrate and invertebrate preparations and include a spectrum of methods ranging from cell biology, superresolution light and electron microscopy to biophysical and electrophysiological analysis. Our understanding of how the structural and functional organization of presynaptic AZs are coupled has matured, as these processes are crucial for the understanding of synapse maturation and plasticity, and, thus, accurate information transfer and storage at chemical synapses.

Keywords: coupling distances, calcium channel positioning, release sites, active zone assembly, AZ scaffold protein superfamilies

Abbreviations: AZ, active zone; BRP, Bruchpilot; $\mathrm{Ca}^{2+}$, calcium; Cac, cacophony; CNS, central nervous system; EM, electron microscopy; ELKS, glutamic acid (E), leucine (L), lysine (K) and serine (S)-rich protein; FRAP, fluorescence recovery after photobleaching; GluRIIA/B, glutamate receptor type IIA/B; HSNL synapses, C. elegans hermaphrodite-specific neuron synapses; LAR, leukocyte common antigen-related; Nlg, neuroligin; NMJ, neuromuscular junction; NT, neurotransmitter; Nrx, neurexin; RIM, Rab3-interacting molecule; RIM-BP, RIM-binding protein; RRP, readily releasable pool; SNARE, soluble NSF Attachment Protein REceptor; Spn, spinophillin; SVs, synaptic vesicles; Syd-1, synapse defective-1; VGCCs, voltage-gated $\mathrm{Ca}^{2+}$ channels. 


\section{INTRODUCTION}

Information processing in neural systems relies on accurate and modifiable communication between neurons at chemical synapses. The arrival of an action potential at chemical synapses elicits a $\mathrm{Ca}^{2+}$ influx through VGCCs at the presynaptic AZ. A fast and local increase of intracellular $\mathrm{Ca}^{2+}$ occurs within the presynaptic bouton and is sensed and translated into a SV fusion event by the SV release machinery. A collection of protein groups constitute the actual SV release machinery, namely SNAREs, (M)Unc13s, (M)Unc18s, complexins, and synaptotagmins, that work in concert to trigger the process of NT release from SVs (Jahn and Fasshauer, 2012).

Synaptic release occurs at defined sites on the presynaptic membrane within an AZ. A multitude of morphological "AZ designs" exist across synapse types and species that, however, are all morphologically characterized by the presence of an electron-dense projection, VGCCs, and SVs at the presynaptic terminus, which together facilitate NT release. Release sites are elaborately assembled by a conserved set of proteins specialized to convey the speed and precision of synaptic transmission (Zhai and Bellen, 2004). Synapses themselves are highly diverse and are grouped based on their differences in response to synapse response time (fast and slow synapses), signal strength, and ability to adapt to signal trains (Gjorgjieva et al., 2016; Jackman and Regehr, 2017). Obviously, variations in the AZ protein composition have evolved to adapt to the functional output of AZs and the synaptic properties on short- and long time scales (Gundelfinger and Fejtova, 2012; Ehmann et al., 2014; Ackermann et al., 2015; Wichmann and Moser, 2015; Van Vactor and Sigrist, 2017). Consequently, synapses can exhibit both high and low transmission fidelity. Work from the past few years has embraced the notion that functional synaptic modulation is essential for directing and programming sensory information within neuronal networks in the brain (Chabrol et al., 2015; Jackman and Regehr, 2017). A number of factors influence the activity-driven functional propensity of synapses to weaken and/or strengthen over time, a spectrum of features collectively referred to as synaptic plasticity. These include factors that may modulate the pre- and postsynaptic sites such as the number, density and location of SVs, VGCCs, postsynaptic receptors, and proteins of the SV fusion machinery (O'Rourke et al., 2012). Topological relations between these molecular players at the nanometer ("nanoscale") level are now believed to be crucial in defining synaptic efficacy and plasticity and will be discussed in detail below.

Short-term synaptic plasticity refers to forms of rapid and activity-dependent modulations of the efficacy of synaptic transmission, allowing preferred signaling frequencies to behave as temporal filters for synaptic transmission (Hennig, 2013; Jackman and Regehr, 2017). Biophysical studies have come to the consensus that SV release probability and, ultimately, shortterm plasticity are fundamentally influenced by the physically coupled distances between VGCCs, and the SVs docked at the presynaptic membrane (Regehr, 2012; Vyleta and Jonas, 2014). During synaptic transmission, SVs sense a VGCC-mediated $\mathrm{Ca}^{2+}$ influx through their $\mathrm{Ca}^{2+}$ sensor, synaptotagmin, which, in turn, triggers SV fusion in the vicinity of the VGCCs, thus delimiting the SV-VGCC coupling distances at the presynaptic membrane (Wadel et al., 2007; Eggermann et al., 2012; Vyleta and Jonas, 2014; Wang et al., 2016a). Tight coupling occurs within the "nanodomain range" at synaptic sites in which VGCCs and SVs, with their sensors, can apparently be as close as only $10-20 \mathrm{~nm}$ and well below $100 \mathrm{~nm}$. By contrast, synaptic sites that exhibit loose coupling have their VGCC and SV sensors located farther apart, in the "microdomain range" that spans a region larger than $100 \mathrm{~nm}$. Tight coupling has been associated with synapses that present high release probabilities but here, due to the high release probability, trains of action potentials tend to deplete the SV pools (depressing synapses). By contrast, loose coupling is associated with low release probabilities but typically associated with high-frequency facilitation (Eggermann et al., 2012; Vyleta and Jonas, 2014). Effective coupling distances, with their influence on short-term plasticity, vary across synapse types to possibly provide functional diversity over the brain (Eggermann et al., 2012; Fulterer et al., 2018).

While the molecular mechanisms and proteins controlling these "coupling distances" had remained rather enigmatic for a long time, a few conserved families of $\mathrm{AZ}$ proteins have now come forward as regulators of this process. We will revisit, here, the evidence suggesting that these $\mathrm{AZ}$ proteins not only mediate tenacity to the ultrastructure of presynaptic AZs but also seem to define stable sites of SV release at the presynaptic membrane, henceforth referred to as release sites. Questions of how such molecular architectures might establish support to SV release sites and how they come to be tightly connected to each other during development are only recently being answered.

The accessibility of Drosophila NMJ synapses to a spectrum of in vivo approaches, from physiology and intravital imaging to genetics, has made the NMJ a useful platform to study synapses and their AZ initial assembly and subsequent maturation. Here, we review the molecular architecture and organization of Drosophila AZs and show how these molecular scaffolds instruct the location of release sites. While placing particular emphasis on the NMJ synapse, we will consider how mechanisms identified at the NMJ synapse may relate or contrast to the operation of other invertebrate or mammalian synapses, toward providing a current and comprehensive understanding of how release sites form and might be regulated.

\section{DEFINED STABLE RELEASE SITES: AN EMERGING CONCEPT}

Chemical synaptic transmission occurs upon the fusion of SVs at the presynaptic plasma membrane to release the NT stored within. This concept was established by the work done between the 1950s and 1970s, where electrophysiological studies addressing the release of NTs were combined with ultrastructural observations that emerged following the advent of EM. A series of studies by Katz and colleagues on motor neuron NMJ synapses of the frog demonstrated that the release of NTs occurs as a discrete packet ("quantal unit") rather than as a continuous event (Fatt and Katz, 1952; Del Castillo and Engbaek, 
1954; Katz, 1971). These observations were coupled to the first ultrastructural visualizations of synapses. Here, electron-dense regions at the pre- and postsynaptic membrane were observed, pointing toward the presence of proteinaceous specializations. Moreover, the presence of uniformly sized, membrane-bound vesicular structures representing SVs provided the morphological equivalent of the physiologically demonstrated quantal units (De Robertis and Bennett, 1955; Rebhun, 1956; Heuser et al., 1979). Today, SV fusion-mediated chemical transmission is the established synaptic transmission concept that has informed the advances in understanding the functions and organization of presynaptic $\mathrm{AZ}$ proteins and the regulation of SV fusion in close proximity to VGCCs.

The sites at which SVs might dock and fuse have been named "release sites" (Pulido and Marty, 2017). The initial evidence for the presence of localized sites of release at the presynaptic membrane was provided through recordings of miniature currents studied under the application of hyperosmotic solutions in hippocampal cultures. Overlapping localizations of these mini currents occur at sites of presynaptic activity, marked by presynaptic proteins and fluorescent-molecule dye uptake localizations (Bekkers et al., 1990; Liu and Tsien, 1995; Auger and Marty, 2000). A series of concerted actions between SVs, their sensors and SNARE proteins occur at such release sites to promote effective release in response to an arriving action potential. Here, although the presynaptic terminal hosts many SVs, only a small fraction of the SVs available have the status of being release-ready. This status is acquired as a consequence of the SV's positioning and molecular state. The maximum number of vesicles that can be released per action potential usually determines the number of functionally active release sites and is identical to the pool of release-ready vesicles (Neher, 2015; Delvendahl and Hallermann, 2016; Kaeser and Regehr, 2017).

Theoretical calculations of electrophysiological data suggest that maintaining effective transmission and plasticity at a presynaptic terminal should entail a precise arrangement of docked SVs within a nanometer-range distance directly in the vicinity of an activated VGCC. Upon the arrival of an action potential, the VGCCs are triggered open, causing a rapid and steep influx of $\mathrm{Ca}^{2+}$ into the presynaptic terminal, which is sensed by the SV release machinery that induces the fusion of primed SVs (Meinrenken et al., 2002; Keller et al., 2015; Nakamura et al., 2015). The $\mathrm{Ca}^{2+}$ sensors of the synaptotagmin family, notably synaptotagmin-1 and synaptotagmin-2, promote the fast exocytosis of SVs. EM shows only a small fraction of SVs in the docked state, i.e., in direct contact with the presynaptic plasma membrane. Therefore, only these few SVs possess the fusion competence required for NT release. In order to ensure immediate NT release from an SV, the latter needs to possess the physiological criteria of being a readily releasable vesicle and should be physically docked. After docking but before fusion, SVs might get "primed" through additional biochemical steps (Verhage and Sørensen, 2008; Kaeser and Regehr, 2017). In fact, EM studies of cultured hippocampal synapses show that SVs ultrastructurally docked to the presynaptic membrane might plausibly correspond to the RRP. Here, the processes of SV docking and priming occur simultaneously, and are thus, seemingly the morphological and functional aspect of the same underlying process (Imig et al., 2014). The physical mechanism of SV fusion in itself occurs as a series of well-coordinated reactions that require the concerted action of SNAREs in conjunction with two associate families of priming factors, (M)Unc13 and (M)Unc18 proteins, which are typically essential for the SV release process (Jahn and Fasshauer, 2012; Rizo and Südhof, 2012). A thermodynamically stable, tetrahelical, coiledcoil SNARE complex forms between the SNARE motives of the vesicular protein, Synaptobrevin-2 or VAMP2, and the plasma membrane proteins Syntaxin-1A and SNAP25. This complex provides the energy necessary for the fusion of the SV to the presynaptic membrane by coordinating the binding of the vesicular SNAREs, i.e., VAMP2/Synaptobrevin-2, on the SV, to the target SNAREs Syntaxin-1 (in its open conformation) and SNAP-25 on the plasma membrane. The SNARE complex, thus, facilitates the fusion of the SV membrane into the presynaptic membrane (Jahn and Fasshauer, 2012). Recent studies suggest that the opening of Syntaxin-1 is catalyzed by (M)Unc13, establishing a direct link from the proteins of AZ scaffold to the release machinery at the AZ (Varoqueaux et al., 2002; Ma et al., 2011; Lipstein et al., 2013; Imig et al., 2014; Man et al., 2015).

The detailed structural constituents of release sites and the localization of these proteins within the release sites have only recently come to light. One such recent study shows that the number of the VGCC clusters scales with synaptic size and parallels the number of functional docking sites present at any given AZ. Thus, VGCCs clusters might be present in the close vicinity to each AZ release site (Miki et al., 2017).

Research from several model systems suggests that the number of release sites available limits synaptic transmission and points to a general molecular layout for the largely conserved organization of SV release sites, which, in turn, acts as the fundamental means to control synaptic transmission (Scheuss and Neher, 2001; Müller et al., 2012; Miki et al., 2016). There appear to be only a few defined, active release sites in individual AZs of Drosophila NMJs, vertebrate NMJs, and cerebellar mossy fiber bouton synapses (Neher, 2010; Miki et al., 2016). These synapses seem to possess a preferred subset of release sites, which are repetitively reused, during high-frequency transmission, once primed SVs are replenished. This is supported by a recycling pool of SVs with high vesicular release probabilities which promote the rapid recruitment and fusion of SVs to these release sites (Saviane and Silver, 2006; Gaffield et al., 2009; Melom et al., 2013; Peled et al., 2014; Ritzau-Jost et al., 2014). The Calyx of Held, another important model synapse, employs many release sites in a parallel fashion, with each release site displaying a rather low probability of SV release. The parallel release from these many sites generates high synaptic transmission rates which allow sustained stimulation at these synapses (Neher and Sakaba, 2008; Borst and Soria van Hoeve, 2012). Notably, differentiation in release site functionality within a single AZ may also occur, where release sites at the periphery of an $\mathrm{AZ}$ are expected to be prone to low-release probabilities and have a lower frequency of fusion events, while a higher frequency of fusion is expected at central locations of release sites (Böhme et al., 2016; Reddy-Alla et al., 2017; Byczkowicz et al., 2018). 
In this review, we will delve into the details of the localization, composition, and formation of release sites that mediate both low and high frequency transmission at synapses.

\section{ULTRASTRUCTURAL ORGANIZATION OF ACTIVE ZONES AND RELEASE SITES}

Presynaptic terminals possess proteinaceous assemblages that form a dense, insoluble "cytomatrix" of AZ proteins ("cytomatrix of the AZ"), which in EM is reflected as electron-dense projections that extend from the $\mathrm{AZ}$ plasma membrane into the cytoplasm. Presynaptic AZs organize the SV release machinery by performing four key functions: sequestering SVs to release sites, priming SVs for rapid $\mathrm{Ca}^{2+}$-triggered fusion, localizing VGCCs adjacent to SV release sites, and coordinating transsynaptic signaling for precise alignment of pre- and postsynaptic elements (Südhof, 2012).

In an effort to understand the ultrastructural principles of release site definition, studies employing EM and/or superresolution light microscopy at $A Z$ sites have, over the years, given us a clearer picture of how the AZ building blocks, namely VGCCs, SVs and AZ proteins, interact to build release sites. In addition, these imaging studies have delineated a spectrum of $\mathrm{AZ}$ morphologies or architectures, henceforth referred to as $\mathrm{AZ}$ designs.

Comparing the ultrastructural design of different AZ types allows for a division of AZs into morphologically distinct groups, i.e., those with elaborate electron-dense projections, such as T-bars and ribbons, and those with less prominent dense projections, such as those of C. elegans and AZs present at most vertebrate CNS synapses. Vertebrate and invertebrate sensory synapses and NMJ synapses generally have prominent and well-defined dense bodies, while the ultrastructural elements of vertebrate CNS synapses often appear less prominent in EM (Ackermann et al., 2015).

Early electron micrographs of AZs of vertebrate NMJs revealed dense elongated structures at the presynaptic membrane, constituting double rows of proteins that possibly contain VGCCs and are surrounded by SVs (Couteaux and Pécot-Dechavassine, 1970; Heuser et al., 1979). Consistent with this observation, the ultrastructural "design" at frog NMJ AZs has two rows of SVs that form in parallel toward the outside of an AZ density and likely include their VGCCs (Harlow et al., 2001). Electron micrographs of C. elegans NMJs reveal AZs that have a broad surface of plasma membrane with electron-dense projections at both pre- and postsynaptic sites (Zhai and Bellen, 2004; Stigloher et al., 2011; Ackermann et al., 2015). Vertebrate synapses show related AZ designs. Tomograms of hair cell ribbon synapses and electron micrographs of rodent NMJs exhibit SVs localized between two rows of VGCCs and the AZ density, forming a central station for SVs to dock (Frank et al., 2010). Meanwhile, AZs of vertebrate central synapses are, by and large, less elaborate than AZs of sensory synapses but exhibit fine filamentous projections or "tethers" that connect SVs, located up to $100 \mathrm{~nm}$ from the plasma membrane, thus, obviously "holding them" close to release sites (Siksou et al.,
2007; Zhou et al., 2013; Midorikawa et al., 2014; Ackermann et al., 2015). At Drosophila NMJs, AZs form a platform consisting of a meshwork of filaments overlaying a "pedestal," aptly known as "a T-bar." The filamentous protrusions span approximately $100-200 \mathrm{~nm}$ from the AZ membrane into the cytoplasm, and have VGCCs centered directly under the T-bar "pedestal" and SVs accumulating on the top roof of the T-bar (Jiao et al., 2010; Wichmann and Sigrist, 2010). Similar T-bar-like architectures are generally found at the AZs of both peripheral (such as NMJs) and most central synapses of all insects (Zhai and Bellen, 2004; Hamanaka and Meinertzhagen, 2010; Fulterer et al., 2018). Regardless of the seemingly complicated design of AZs, their core ultrastructure harbors a dense and proteinaceous cytomatrix of AZ material that links the SVs, VGCCs and the presynaptic plasma membrane together. For a detailed description and comparison of the different AZ morphologies in various species and synapses, please refer to the following: Zhai and Bellen (2004), Ackermann et al. (2015), and Slater (2015).

All these different AZ designs probably possess a common concept for the ultrastructural organization at the presynaptic terminus, as they all possess an electron-dense projection at the presynaptic membrane, which contains the AZ protein cytomatrix, SVs that are tethered around these dense projections, and VGCCs that are positioned in the presynaptic membrane in close proximity to SVs. Despite the apparent structural heterogeneity between the AZ ultrastructure of all these various synapse types, their presynaptic AZ sites support the docking of SVs at defined release sites on the presynaptic membrane. During this process, the AZ scaffold takes up various roles in the recruitment and consequent delivery of SVs to the presynaptic membrane. Therefore, a simple and common concept of building the presynaptic AZ ultrastructure also likely instructs the canonical design of release sites and helps define the lateral distances between SVs and VGCCs at these sites.

\section{A Confined and Conserved Set of Extended Proteins for Forming Active Zones}

Recent studies have arrived at a consensus that a defined "set" of scaffold proteins, largely conserved between vertebrates and invertebrates and across different synapse types, form an AZ scaffold at the presynaptic terminus (Owald and Sigrist, 2009; Südhof, 2012; Ackermann et al., 2015). A conserved protein constituency between synapses points to the presence of basic building blocks of $\mathrm{AZ}$ proteins that may supply all $\mathrm{AZ}$ sites and suggest that these proteins are likely at the core of an AZ's principal functionality; based off ancient conserved principles.

These conserved protein complexes entail the following conserved components: the ELKS/CAST/BRP family, the large RIM family (that also includes its more distant members, such as the mammalian Piccolo and Bassoon, as well as Drosophila Fife), the RIM-BP family, the (M)Unc13 family, the Liprin$\alpha /$ Syd-2 and, finally, the Syd-1 family members (Südhof, 2012; Gundelfinger et al., 2016; Petzoldt et al., 2016; Xuan et al., 2017). Together, these $A Z$ proteins are thought to be essential 


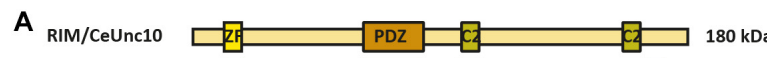
Fife $160 \mathrm{kDa}$ Bassoon 대글
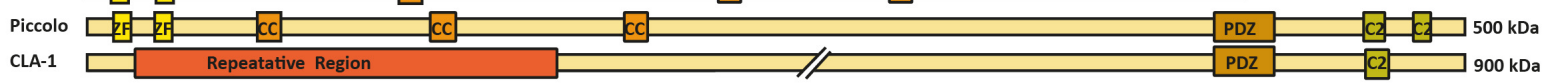

B

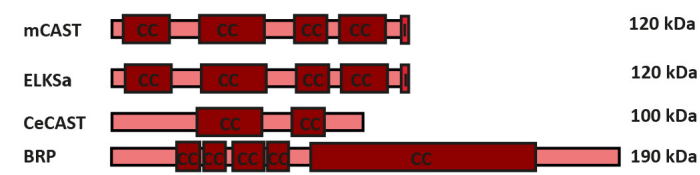

C
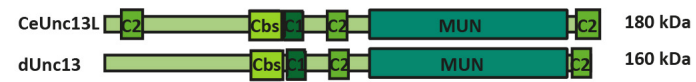
Munc13-1들 Cbs

D

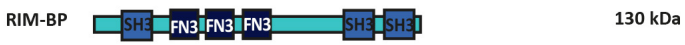
dRIM-BP $\square$ SH3 FFN3FN3

E Syd-2 $\mathrm{CC}$

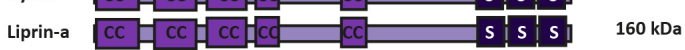

F Syd-1 पPDZ $150 \mathrm{kDa}$

FIGURE 1 | AZ protein superfamilies in invertebrates and vertebrates. Molecular structure of AZ proteins grouped into superfamilies. (A) RIM superfamily is composed of RIM/Unc10, Bassoon, Piccolo, Fife, and Clarinet. These proteins possess an N-terminal zinc-finger domain (ZF), a PDZ domain and two C2 domains. Mammalian Bassoon and Piccolo proteins additionally possess three coiled-coil domains (CC). (B) ELKS/CAST/BRP superfamily of proteins contains multiple CC regions and an additional C-terminal IWA motif in the mammalian isoforms (I). (C) M(U)nc13 superfamily consists of Unc13L (C. elegans), Unc13 (A,B isoforms in Drosophila) and Munc13-1-4 in mammals. These proteins have two/three C2 domains, a calmodulin binding site (Cbs) (with the exception of Unc13B), a C1 domain, and a MUN domain. (D) dRIM-BP (Drosophila) and RIM-BP form a superfamily of AZ proteins that possess an interruption of three contiguous FN3 domains between their first and last SH3 domains (E) Syd-2 /Liprin $\alpha$ family contain five CC regions and three C-terminally located SAM domains. (F) Syd-1 family possess a PDZ domain, C2 domain and a unique Rho-GAP domain.

for synapse tenacity, localization of SVs to their fusion site and positioning of VGCCs.

Proteins within each of these families possess a significant degree of similarity in the fundamental design of their molecular domain structure, which probably allows for a relatively conserved function of these proteins across synapse variations. In this section, we have, therefore, grouped these $\mathrm{AZ}$ proteins into structurally related superfamilies of proteins.

Potentially, the most diversified superfamily of AZ proteins is the RIM (Rab3-interacting molecule) superfamily. This family includes the standard RIM isoforms and Fife (in Drosophila), the recently found CLA-1 (in C. elegans), and the large scaffolding proteins Bassoon, Piccolo and Piccolino (in mammals). These proteins function by providing an interaction surface for a number of AZ proteins, while binding directly to Munc13s and RIM-BPs, thus, promoting close interaction of the linked AZ proteins to the SV release machinery (Dulubova et al., 2005). In addition, these proteins are also involved in VGCC recruitment and clustering, thus, providing $\mathrm{AZ}$ proteins involved in SV release in close proximity to the site of release induction. These interactions are achieved via the PDZ domains, C2 domains and Zinc finger motifs that all these proteins possess in common with each other (Figure 1A) (Dick et al., 2003; Dulubova et al., 2005; Khimich et al., 2005; Lu et al., 2006; Frank et al., 2010; Südhof, 2012; Alvarez-Baron et al., 2013; Xuan et al., 2017).

The CAST and Glutamic acid (E), leucine (L), lysine (K) and serine (S)-rich protein (ELKS) proteins (at mammalian synapses), CeCAST (at C. elegans synapses) and BRP (at Drosophila synapses) superfamily of proteins are characteristic for their continuous coiled-coil architecture. Mammalian ELKS protein is widely expressed over a number of tissue types and has numerous splice variants (Nakata et al., 2002). The more specific expression of CAST protein and ELKS $\alpha$ isoform is brain-specific and present at the AZs of these synapses (Ohtsuka et al., 2002; Deguchi-Tawarada et al., 2004). In addition, these proteins share up to $70 \%$ protein homology with one another and, due to this similarity, are proposed to have related but discrete functions within a synapse, as they reportedly localize at different positions within the AZ site (Ohtsuka et al., 2002; Deguchi-Tawarada et al., 2006). For a comprehensive overview of the diverse functional roles of synaptic and non-synaptic ELKS that bolster the protein's role as an intrinsic scaffold protein and an organizer of SV traffic please see the review of Kaeser and Held (2018). One representative protein member each from this superfamily is found in the C. elegans and the Drosophila model systems, namely CeCAST and BRP, respectively (Figure 1B) (Kittel et al., 2006; Wagh et al., 2006). Proteins of this superfamily all possess four or five conserved coiled-coil regions. However, the mammalian CAST/ELKS members possess a C-terminal IWA motif, which is required for binding to RIM1's PDZ domain, that is not present in their invertebrate counterparts. On the other hand, at Drosophila synapses, the N-terminal half of BRP resembles the N-terminal region of mammalian ELKS/CAST, but it also harbors an extended C-terminal region, only present in insects, 
that forms the T-bar pedestal present at their AZs (Hida and Ohtsuka, 2010).

The third superfamily of proteins is that of $(\mathbf{M}) \mathrm{Unc13}$ proteins which connects the scaffold proteins to the actual SV fusion machinery. (M)Unc13 superfamily members possess a general domain structure that includes at least one MUN domain, a $\mathrm{C} 1$ domain, a $\mathrm{C} 2$ domain and often a $\mathrm{Ca}^{2+}$-calmodulin and diacylglycerol-binding site. This general domain design comes with an exception for Munc13-4/Unc13D, which lack the $\mathrm{Ca}^{2+}$ calmodulin and diacylglycerol binding sites (Koch et al., 2000; Crozat et al., 2007; Dudenhöffer-Pfeifer et al., 2013). The MUN domain is used in the protein family's central function of SV priming and release by enabling the transition from the Munc18-1 closed syntaxin-1 complex into the SNARE complex (Richmond et al., 2001; Basu et al., 2005; Ma et al., 2011). In addition, many isoforms of this protein family display a $\mathrm{Ca}^{2+}$. calmodulin binding site close to their $\mathrm{C} 1$ and $\mathrm{C} 2$ domains. The $\mathrm{C} 2$ domain itself binds $\mathrm{Ca}^{2+}$ and phosphatidylinositol phosphates, which, in turn, potentiate release probability (Shin et al., 2010) (Figure 1C), while the $\mathrm{C} 1$ domain is involved in diacylglycerol phorbol ester-dependent regulation of SV release (Rhee et al., 2002; Basu et al., 2007) (Figure 1C). There are four vertebrate Munc13 members (Munc13-1-4) of which Munc13-1-3 are brain specific, while the Drosophila and the C. elegans systems have fewer Unc13 members each; namely, Unc13A and B and Unc13L, S and D, respectively (Brumell et al., 1995; Dulubova et al., 2005; Lu et al., 2006; Böhme et al., 2016). These proteins are crucial for promoting SV docking and regulation of SV fusion at the respective synapse types, at which they are found (Dulubova et al., 2005; Lu et al., 2006; Böhme et al., 2016; Reddy-Alla et al., 2017).

The RIM-BP superfamily members are important for the structural integrity of the AZ scaffold and probably also play direct roles in organizing protein architectures for NT release. These proteins have three $\mathrm{SH} 3$ binding domains in common, interrupted by three contiguous fibronectin-type III domains (Figure 1D). The first SH3 domain of the mammalian RIM-BP has been found to interact with $\mathrm{AZ}$ protein Bassoon, while the last SH3 domains of RIM-BP and dRIM-BP (Drosophila RIMBP) are involved in the direct interaction to RIM1 and VGCCs (Wang et al., 2000; Hibino et al., 2002; Liu et al., 2011). The RIMBP's direct interactions to VGCCs link them to release sites and to RIMs, allowing RIM-BPs to regulate VGCC positioning at the presynaptic AZ site (Hibino et al., 2002; Kaeser et al., 2011).

The Liprin- $\alpha /$ Syd-2 superfamily of proteins was originally found as binding partners to tyrosine phosphatase LAR. All Liprin- $\alpha$ isoforms possess a highly similar domain organization (Figure 1E), consisting of coiled-coil domains that provide interaction surfaces for binding to several synaptic adapter proteins, including CAST, GIT1, RIM, and KIF1A, to their $\mathrm{N}$-terminal region (Schoch et al., 2002; Ko et al., 2003; Shin et al., 2003). At their C-terminal end three sterile alpha motif (SAM) domains are found, which possess binding sites to both protein phosphatases (e.g., LAR, PTP $\delta$ and PTP $\sigma$ ) and protein kinases (e.g., CASK). These regions also promote heterodimerization between Liprin isoforms, (Serra-Pagès et al., 1995). Two families of vertebrate Liprins exist as Liprin- $\alpha$ and Liprin- $\beta$, and have these four $(\alpha 1, \alpha 2, \alpha 3$, and $\alpha 4)$ and two ( $\beta 1$ and $\beta 2)$ members, respectively (Serra-Pagès et al., 1995, 1998). In invertebrates, Drosophila has only one member of Liprin- $\alpha$ and $\beta$ each, also known as Liprin- $\alpha / \beta$, while the $C$. elegans encode only a single Liprin- $\alpha$ isoform called Syd-2 (Zhen and Jin, 1999; Kaufmann et al., 2002). The Liprin- $\alpha /$ Syd-2 superfamily members have key roles in AZ formation as they bind to a number of AZ superfamily members such as, Syd-1, Unc13, RIM, and ELKS, thus sequestering them to developing AZs (Ohtsuka et al., 2002; Schoch et al., 2002; Wang et al., 2002; Ko et al., 2003; Dai et al., 2006; Patel et al., 2006; Ackermann et al., 2015).

Synapse defective-1 (Syd-1) falls into a group of its own, as it is structurally dissimilar to the Liprin- $\alpha$ family. This protein was first discovered in C. elegans and has been heavily investigated for its ability to regulate $\mathrm{AZ}$ assembly at invertebrate synapses. The Syd-1 protein shares certain structural similarities to the RIM family, in that it possesses a PDZ and C2 domain, with the exception that Syd-1 has its own signature rho-GTPase activating protein domain, which is not shared by any other AZ superfamily. Syd- 1 is involved in promoting BRP clustering and AZ assembly at Drosophila AZs, and neurite outgrowth in C. elegans (Hallam et al., 2002; Owald et al., 2010; Spinner et al., 2017) (Figure 1F).

Members from each of these superfamilies are required in concert to coordinate AZ structural assembly as well as AZ functionality, probably to a good degree by providing SV release sites at a defined distance from the VGCCs. The details of these aspects will be a central topic of discussion in the following sections.

\section{Functional Roles of Active Zone Scaffold Proteins}

A body of work has established that AZ scaffold proteins promote SV priming and docking, help confer suitable SV release probability, and are responsible for the localization of VGCC to AZs and release sites (Kaeser et al., 2011; Acuna et al., 2015; Grauel et al., 2016; Reddy-Alla et al., 2017). In an effort to understand their individual role, more than a decade of work employing super-resolution light microscopy and EM, combined with biochemical and electrophysiological analyses on loss-of-function mutants of AZ proteins have revealed the many interaction partners and the partial functional redundancies in the roles of AZ scaffold proteins (Kittel et al., 2006; Kaeser, 2011; Liu et al., 2011; Müller et al., 2012; Liu et al., 2014; Acuna et al., 2015).

A series of structure-function analyses from individual and double-mutant loss-of-function experiments have come a long way in revealing AZ scaffold core functions in SV release, VGCC localization, and coupling at invertebrate synapses. Only one VGCC $\alpha 1$ subunit isoform Cac is expressed at Drosophila NMJ synapses, which corresponds to the mammalian CaV2.1/2.2 (N or $\mathrm{P} / \mathrm{Q}$ type VGCCs) and is responsible for synaptic transmission at these synapses. Null mutants of cac are embryonically lethal, probably due to their nearly complete incapability to permit any evoked SV release (Kawasaki et al., 2002; Hou et al., 2008). Intracellular binding partners of Cac, thus, possess the proclivity to influence synaptic transmission. Only a few Drosophila AZ 
scaffold proteins possess such interactions with Cac, of which BRP is a core AZ scaffold member (Fouquet et al., 2009).

BRP is present as both a $170 \mathrm{kDa}$ (short) and a $190 \mathrm{kDa}$ (long) isoform at NMJ synapses. The latter isoform possesses an additional and exclusive N-terminal domain that the BRP$170 \mathrm{kDa}$ isoform lacks. At NMJ AZs, the two isoforms form discrete oligomers that alternate in a circular array to form a donut-shaped structure centered at the $\mathrm{AZ}$ site, as was visualized by sub-diffraction resolution stimulated emission depletion (STED) fluorescence microscopy (Kittel et al., 2006; Matkovic et al., 2013). The BRP protein forms an intrinsic component of the synapse's prominent electron-dense T-bar structure and shapes it directly (Wagh et al., 2006; Fouquet et al., 2009). Subsequent work employing super-resolution microscopy approaches such as; STED applications and direct stochastic optical reconstruction microscopy, have revealed the precise nanoscopic localization of BRP within the AZ, and revealed that BRP signals when resolved appear as polarized filamentous proteins that possess an elongated and oriented structure, wherein their $\mathrm{N}$-termini face the presynaptic membrane, while their C-termini extend into the bouton's cytoplasm (Fouquet et al., 2009). In addition, these studies show that the nanoscopic organization of BRP, within an AZ, can demarcate the different physiological states the $\mathrm{AZ}$ undergoes and along with the resolved localizations of other AZ components, such as VGCCs, RBP, Syd- 1 and Liprin- $\alpha$, have begun to provide an increasingly detailed picture of the $\mathrm{AZ}$ scaffold at Drosophila NMJs (Fouquet et al., 2009; Owald et al., 2010; Liu et al., 2011; Maglione and Sigrist, 2013; Ehmann et al., 2014).

Previous studies of the NMJ synapse have shown clustering of Cac at presynaptic AZ membranes (Kawasaki, 2004). This Cac clustering becomes inefficient at BRP mutant AZs, which also display a complete loss of their T-bar structures and inefficiently evoked SV release observed in response to discrete action potentials. However, brp null mutants showed an atypical facilitation in response to higher frequencies of action potentials (Kittel et al., 2006). This changed short-term plasticity suggests an increased distance between Cac and release-ready SVs. Consistently, an increased sensitivity versus slow $\mathrm{Ca}^{2+}$ chelator EGTA-AM was observed at these mutant synapses, suggesting an altered coupling, from tight to loose, between VGCCs and SV-Ca ${ }^{2+}$ sensors and, thus, revealing a fundamental role for BRP in VGCC localization (Kittel et al., 2006). This relationship was further established in a later study where the $\mathrm{N}$-terminal region of the $\mathrm{BRP}$, in its $190 \mathrm{KD}$ isoform, was found to bind directly to the intracellular C-terminal region of Cac and solidified BRP's function in organizing the VGCC's nanodomains at the presynaptic AZ site (Fouquet et al., 2009).

While the N-terminal region of BRP is conserved and similar to other members of its superfamily, BRP's C-terminus seemingly plays a significant role in SV recruitment, unlike its mammalian superfamily members (Hallermann et al., 2010). A study at NMJ synapses describing a hypomorph allele of brp ("brp-nude"), which is devoid of only the very last $1 \%$ of its C-terminal sequence, revealed properly formed T-bar structures atop undisturbed VGCC localizations at the presynaptic membrane.
These T-bar structures, however, lack the normal and expected accumulation of SVs atop the T-bar distal aspect (or "roof").

Electrophysiological recordings at these mutant synapses showed unaltered basal SV release, while paired-pulse protocols provoked an atypical depression and sustained stimulations caused an atypically slow recovery (Hallermann et al., 2010). These results link the AZ scaffold's ability to tether SVs directly with SV recruitment. The BRP protein possibly engages in physically moving these SVs to precise localizations on the presynaptic membrane and into release slots, thus, facilitating efficient sustained release at an AZ site.

In contrast to the observations of the brp null mutants, the isoform-specific BRP mutants (lacking either the 190 or the $170 \mathrm{kDa}$ isoform) did not show major Cac clustering or SV release probability deficits although the basal synaptic transmission was reduced, as a result of the reduced numbers of SVs in the RRPs. Consistently, the number of docked SVs were also significantly reduced, suggesting the BRP architecture at the AZ site may be involved in regulating the RRP size by influencing the number of VGCC-coupled SV release sites (Matkovic et al., 2013). Extended studies on isoform-specific BRP mutants have also shown that the N-terminal Cac-binding region of BRP, unique only to its $190 \mathrm{kDa}$ isoform, is not sufficient for a complete declustering of VGCCs. This would suggest an involvement of multiple AZ scaffold proteins that probably employ a collective mechanism to anchor VGCCs to the presynaptic membrane (Matkovic et al., 2013). This may certainly be a mechanism employed at the AZ site, since the RIM-BP superfamily members also bind VGCCs at rodent and Drosophila AZs directly, and display a partial loss of VGCCs at drim- $b p$ null NMJs (Wang et al., 2000; Hibino et al., 2002; Matkovic et al., 2013). In addition, STED microscopy of dRIM-BP at NMJ Drosophila synapses shows that the protein is localized to the AZ core, overlaying the central AZ localizations of $\mathrm{Cac}$, thus, physically positioning $\mathrm{dRIM}-\mathrm{BP}$ as a prime candidate for nanodomain coupling at AZ sites (Liu et al., 2011).

A series of studies at Drosophila NMJ synapses involving drim- $b p$ null mutants and a dRIM-BP hypomorph (with 30\% residual expression) uncovered a dramatic effect on AZ scaffold ultrastructure and synaptic transmission. The drim- $b p$ null mutants displayed $90 \%$ reduction in baseline transmission, while the frequency and amplitude of their miniature excitatory junctional currents remained unchanged, causing a dramatic reduction in the number of SVs released per action potential in these mutants. In addition, a $10 \mathrm{~Hz}$ paired-pulse stimulation assay on drim-bptop 1 null mutant AZs was met with a strong facilitation, although a consecutive five-pulse, $100 \mathrm{~Hz}$ stimulation was met with a sizable recovery that matched control levels. Taken together, this work demonstrates that SV release probability in dRIM-BP mutants is severely affected, although the SV release itself may be raised back to rather normal levels under highfrequency stimulation, arguably implying that dRIM-BP does not influence the SV fusion process or release machinery but rather an upstream component (Liu et al., 2011). In addition, evoked SV fusion events appeared desynchronized at these synapses as a significantly increased excitatory junctional current rise time was observed. In addition, Cac-GFP signals were consistently reduced by $\sim 25 \%$ over the entire NMJ of all three dRIM-BP null 
alleles and the hypomorphic allele. The drim- $b p$ null mutants also exhibit an altered ultrastructure of the electron-dense material, as the T-bars of these mutant AZs appear severely misshapen (Liu et al., 2011). Overall, loss of drim-bp function results in ultrastructural changes and severe impairment of baseline SV transmission, possibly as a result of disturbed SV-VGCC coupling, leading to desynchronized release at the presynaptic membrane (Liu et al., 2011).

In addition, the RIM superfamily of proteins has also been shown to regulate baseline synaptic transmission, cluster VGCCs and facilitate SV priming at mammalian AZs. The RIM function at Drosophila NMJ AZs appears evolutionarily conserved, as rim null mutants displayed baseline SV release deficits, lowered $\mathrm{Ca}^{2+}$ influx and channel number, reduced RRP size and a decrease in $\mathrm{AZ}$ numbers, resulting in a severe impairment of evoked SV release at these synapses (Graf et al., 2012; Müller et al., 2012). The drim-bp mutations generally display a stronger defect in baseline transmission followed by a dramatic facilitation when compared to the rim mutants, although both mutants show consistent defects in SV transmission and $\mathrm{Ca}^{2+}$ influx, thus, implicating the presence of a protein complex that works in a coordinated fashion. In addition, although VGCC numbers are reduced in rim mutants, the core scaffold protein BRP remains unaffected and tagged RIM expression in brp mutants of Drosophila and C. elegans synapses appears undisturbed at AZ sites. This suggests that BRP is not involved in RIM localization to release sites (Deken et al., 2005; Graf et al., 2012). Furthermore, these results suggest that these AZ scaffold proteins may perform partially overlapping roles here, as the disruption of only one of the RIM, dRIM-BP, or BRP proteins does not completely eliminate VGCC localization at their release sites.

An interesting additional function of the RIM protein in regulating synaptic homeostasis was uncovered in loss-offunction rim mutants at NMJ synapses. Homeostatic modulation of presynaptic NT release is an evolutionarily conserved form of plasticity documented at the NMJs of a number of systems, from Drosophila to humans, and occurs upon a postsynaptic NT receptor block that elicits an increase in SV release, offsetting the magnitude of receptor inhibition precisely. No homeostatic enhancement of SV release occurs at Drosophila NMJs of rim null mutants during a postsynaptic receptor inhibition. Two presynaptic processes are critical for synaptic homeostasis. The first is the enhancement of presynaptic $\mathrm{Ca}^{2+}$ influx to potentiate SV release, which, despite the initial baseline $\mathrm{Ca}^{2+}$ influx defect, can be re-sequestered during homeostasis in rim null mutants. The second is the provision of an enhanced RRP size, which is blocked in rim null mutants and, hence, a RIMdependent modulation of the RRP size appears to be essential for the homeostatic plasticity response (Müller et al., 2012). A recent study has shown that the $\alpha 2 \delta-3$ subunit of VGCCs functions together with RIM, either directly or indirectly, to achieve a homeostatic potentiation of the RRP size and may, in concert with other proteins at the release site, regulate synaptic homeostasis (Wang et al., 2016b).

Taken together, deletions of members of the RIM, ELKS/BRP and RIM-BP superfamilies at Drosophila synapses display disrupted AZ scaffold structures. This ultrastructural effect is compounded by impaired SV priming and, subsequently, SV transmission in rim- $b p$ mutants, and impaired VGCC clustering in the brp mutants. Meanwhile, RIM proteins probably operate downstream of BRP and RIM-BP function, as they potentiate the homeostatic regulation of the RRP size at AZs; this RIMmediated effect can be perceived in the presence of unaltered BRP-regulated $\mathrm{Ca}^{2+}$ influx and RBP-mediated SV priming and SV release (Kittel et al., 2006; Fouquet et al., 2009; Liu et al., 2011).

Furthermore, these results concur with data from vertebrate synapses. Here, RIM and ELKS, through an exhaustive cohort of biochemical studies, have been shown to interact with a number of other AZ scaffold proteins and obviously function by providing a smart scaffold surface for other AZ proteins and potentially the release machinery to bind to. Individual knockout studies of these proteins, however, do not paint a clear picture (Ohtsuka et al., 2002; Schoch et al., 2002; Wang et al., 2002; Takao-Rikitsu et al., 2004). Individually, RIM1, RIM2, ELKS-1 and ELKS2 knockout mice have largely intact AZ scaffolds, with the remote changes observed in SV clustering, levels of Munc13-1 in the RIM knockouts and an increased RIM solubility in the ELKS knockout studies (Schoch et al., 2002; Kaeser et al., 2009; Deng et al., 2011; Liu et al., 2014; Held et al., 2016). Importantly, however, deletion of all RIMs in mice perturbs the localization of VGCCs, as well as SV priming and tethering, while, even here, the gross AZ scaffold architecture remained rather unchanged (Han et al., 2011; Kaeser et al., 2011). Deleting RIM-BP1 and RIM-BP2 proteins at synapses of cultured hippocampal neurons and Calyx of Held synapses had only a mild effect on SV release and no clear structural effect (Acuna et al., 2015). Through these studies, it appears that loss of individual AZ proteins could be largely compensated, again suggesting at least a certain degree of functional "redundancy" between AZ scaffold proteins. This is probably because vertebrates encode several loci and gene products of relevant genes that, in turn, complicate their analysis. Such findings have motivated the simultaneous deletion of representatives from distinct $\mathrm{AZ}$ superfamilies to expectantly perturb the AZ scaffold in its entirety. Indeed, quadruple knockouts of RIM1, RIM2, RIM-BP1 and RIM-BP2 proteins in mice exhibit a total loss of NT release from severe impairments in SV priming and docking, a dramatic loss of AZ scaffold density, and a trans-synaptic effect that disrupts the organization of the postsynaptic density (Acuna et al., 2016). This study revealed a redundancy in the role of the two RIM and RIMBP protein families in maintaining global AZ functions. Similar conclusions were also drawn from work on mice completely devoid of RIM $1 \alpha \beta$ and RIM $2 \alpha \beta \gamma$, together with ELKS1 $\alpha$ and ELKS $2 \alpha$ isoforms (Wang et al., 2016a). Consequently, cultured hippocampal synapses of these mutant mice lose Munc13, Bassoon, Piccolo and RIM-BP following a mass disassembly of the AZ scaffold (Wang et al., 2016a).

The RIM, RIM-BP and ELKS superfamilies of proteins, at vertebrate and invertebrate synapses, function collectively to structurally and functionally uphold the organization of the AZ scaffold. Within the AZ scaffolds, AZ superfamily members BRP, RIM-BP, and RIMs support VGCC clustering at AZs and through their interaction concentrate VGCCs and the $\mathrm{Ca}^{2+}$ influx. This, in turn, would enable regulation of release probability and 
promote evoked SV release (Wadel et al., 2007; Kittelmann et al., 2013; Ehmann et al., 2015; Van Vactor and Sigrist, 2017). In addition, the AZ superfamily members mentioned have been implicated in the direct maintenance of release sites and VGCC density, while their sheer protein levels can also predict an $\mathrm{AZ}$ site's release probability (Kittel et al., 2006; Wagh et al., 2006; Han et al., 2011; Kaeser et al., 2011; Liu et al., 2011; Acuna et al., 2015). Therefore, taken together, these studies implicate AZ scaffold proteins in localizing VGCCs and release factors to appropriate positions to execute their function in SV release.

\section{Toward a Molecular Definition of Release Sites}

A priori, release site-regulating protein should be located at the release site on the presynaptic membrane, and likely becomes stably integrated at this given site. Moreover, these proteins might take a role in SV priming and/or ultrastructural SV docking to the presynaptic membrane.

Recent work on Drosophila NMJ synapses shows that the $\mathrm{M}(\mathrm{U}) \mathrm{nc13}$ superfamily member, Unc13A, fulfills all the criteria for a release site-generating molecule (Böhme et al., 2016). STED imaging reveals Unc13A clusters positioned in close proximity to VGCCs at precise localizations within the AZ, i.e., at a $70 \mathrm{~nm}$ distance from the centrally located VGCC clusters. A novel assay that employs the postsynaptic expression of fluorescent $\mathrm{Ca}^{2+}$ indicators (GCaMPs) allows the recording of events of evoked and spontaneous release at individual NMJ AZs (Melom et al., 2013; Peled et al., 2014; Walter et al., 2014; Muhammad et al., 2015). Applying this assay revealed that presynaptic Unc13A levels could predict the probability of a given AZ to engage in an AP-evoked release. Meanwhile, the ultrastructural data showed Unc13A cluster positions coinciding with the locations of docked SVs. In addition, these Unc13A clusters were found to be highly stable, as intravital live imaging studies, followed by a FRAP assay, reveal only a very slow turnover of this protein, which only occurs over a span of hours, ensuring its stable integration at AZ release site locations (Figures 2H,I) (Böhme et al., 2016). Lastly, but most importantly, deleting the scaffold-binding $\mathrm{N}$-terminus of Unc13A changes the localization, position, and efficacy of $\mathrm{SV}$ release sites and undermines the scaling of evoked release events and AZ size (Reddy-Alla et al., 2017). All these studies clearly implicate Unc13A as the release site defining protein at Drosophila synapses. Interestingly, in brp-rim-bp, as well as in rim-elks and rim-rim-bp double mutants, the synaptic localization of the release site-generating molecules, Unc13A and Munc13-1, at Drosophila and vertebrate synapses, was largely impaired, conforming to the loss of release sites observed in these mutants, thus, demonstrating a close-knit relation between the AZ scaffold and release site regulation (Acuna et al., 2015; Böhme et al., 2016; Wang et al., 2016a).

A recent study by Sakamoto et al. (2018) combined glutamate sniffers, which sense glutamate release at high signal to noise ratios, to couple imaging of quantal release events with superresolution imaging of $\mathrm{AZ}$ components. Consistent with the work at Drosophila synapses, this elegant analysis showed that Munc13-1 but not SNAREs localize stably to active glutamate release sites (Sakamoto et al., 2018). Local "supramolecular" Munc13-1 assemblies seem to provide a local surface to which open syntaxin-1 molecules can bind, that, in turn, generates activated SNARE complexes to locally promote SV priming and docking at these sites. In other words, this study agrees that stable $(\mathrm{M})$ unc13 clusters form release sites at the presynaptic AZ membrane.

Taken together, it seems that the mechanistic rationale behind an AZ scaffold localizing in the close vicinity of VGCCs clusters and the SV fusion machinery is to provide a stable platform for (M)Unc13 superfamily members to generate and regulate release sites.

\section{Release Sites and the Control of SV-VGCC Coupling}

For a long time, coupling distances, defined as the physical distance from the closest VGCC to the $\mathrm{Ca}^{2+}$ sensors, present on SV membranes, were a purely biophysically derived entity and the relevant proteins creating such distances were themselves not visualized. Measuring differential sensitivity of SV release versus exogenous $\mathrm{Ca}^{2+}$ buffers, EGTA and BAPTA, that vary in their $\mathrm{Ca}^{2+}$ sequestering speeds, was a dominant assay to biophysically measure effective coupling distances at a variety of synapses. These measurements predicted a spread of effective coupling distances, being $10-20 \mathrm{~nm}$ at the basket cell-Purkinje cell synapses and basket cell-granule cell synapses, $<30 \mathrm{~nm}$ at the granule cell-Purkinje cell synapses, $30-60 \mathrm{~nm}$ at the Calyx of Held synapses, and $\sim 65-90 \mathrm{~nm}$ at the CA3 pyramidal cell synapses of mossy fibers (Bucurenciu et al., 2008; Schmidt et al., 2013; Arai and Jonas, 2014; Vyleta and Jonas, 2014; Nakamura et al., 2015). A series of recent studies have now begun to link super-resolution imaging with electrophysiology, mathematical modeling, and genetics to explore the physical basis of coupling distances.

The (M)unc13 superfamily of proteins have been recently identified as the release site-generating component (Böhme et al., 2016; Sakamoto et al., 2018). Taking into account that the distance from release sites to VGCCs instruct the efficacy of release, synaptic transmission speed and, ultimately, shortterm plasticity, the next eminent step was to determine physical distances between the VGCCs and (M)Unc13 superfamily members (Eggermann et al., 2012; Vyleta and Jonas, 2014).

Recent efforts to obtain visual evidence of VGCC coupling distances to release sites have employed a combination of superresolution imaging at the Drosophila NMJ synapses. Here, STED imaging has revealed a central localization of VGCC alpha1 subunit- Cac, directly under the BRP scaffold (Fouquet et al., 2009). At these synapses, STED resolved images have allowed distance measurements from a VGCC cluster center to the (M) Unc13 cluster position (note that coupling distances in other studies have been measured as the distance between SVs and the respective closest VGCC). Taking advantage of the "neatly arranged" AZs of Drosophila, the distances from Unc13A at the presynaptic membrane, to the central localizations of Cac were measured from STED images and electron micrographs of T-bar structures, Both techniques measured Unc13A-VGCC 

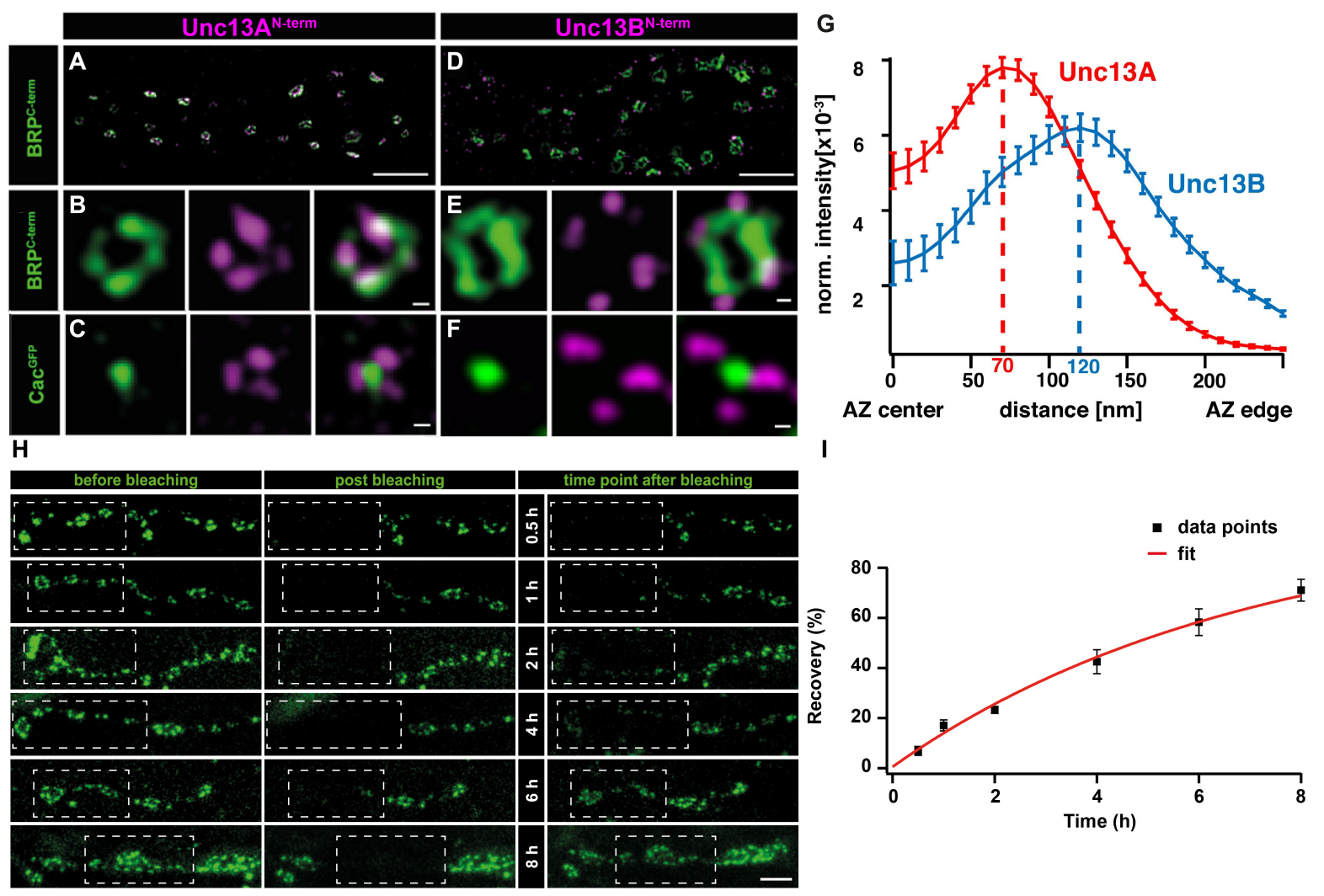

FIGURE 2 | Stable and specific positioning of Unc13A and B at Drosophila NMJ synapses. (A,D) Two-color STED microscopy images of synaptic boutons or individual planar AZs (B,C,E,F) from third instar larvae of the displayed genotypes labeled with antibodies to indicated proteins. (G) Mean intensity profile of Unc13A and Unc13B immunoreactivity plotted from the center of the AZ (the reference center being that of the BRP signal). The intensity maximum of the average fluorescence profile was found $70 \mathrm{~nm}$ from the AZ center for Unc13A and at $120 \mathrm{~nm}$ for Unc13B. Scale bars: (A,D): $1.5 \mu \mathrm{m} ; \mathbf{( B , C , E , F ) : 5 0 ~ n m ; ~ ( H ) ~} 250 \mathrm{~nm}$ (Modified from Böhme et al., 2016). (H) Long-term FRAP of motoneuronally overexpressed Unc13A-GFP at muscle 26/27 depicts a stable integration of Unc13A that requires hours to recover completely. Dashed box shows bleached bouton before and directly after the fluorescence bleaching. Fluorescence recovery was measured 0.5 ; 1 ; 2; 4; 6; or $8 \mathrm{~h}$ after bleaching. Different time points were measured in different animals. (I) Quantification of percentage recovery over time. Bleached Unc13A-GFP showed a slow fluorescence recovery, exhibiting a tau of $6.88 \pm 0.55 \mathrm{~h}$, single exponential recovery fit. Data are mean \pm SEM. Scale bar:5 $\mu \mathrm{m}$ (Modified from Reddy-Alla et al., 2017). Reproduced with permission, from Böhme et al., 2016 (A-G) and from Reddy-Alla et al., 2017 (H,I).

cluster to cluster distances of 50-70 nm (Figures 2A-G) (Böhme et al., 2016). In addition, Unc13A mutagenesis experiments show that the N-terminal region of Unc13A mediates release site positioning, with deletions in this region resulting in highly mobile and unspecific positioning of Unc13A across the presynaptic membrane, which, in turn, enabled docking of SVs in aberrant positions. Functionally, this situation resulted in an unusually strong facilitation and loss of temporal precision of SV release (Reddy-Alla et al., 2017).

\section{ACTIVE ZONE ASSEMBLY}

Thus far, we have discussed how release sites are ultrastructurally and molecularly organized at matured synapses. Though it is of crucial importance for the understanding of circuit remodeling during development and learning processes, how in fact do AZs assemble during these processes. We still know relatively little about AZ assembly during development, and this comes mostly from invertebrate preparations. We describe in the following section emerging principles by which AZ scaffolds seem to assemble, and how these assembly processes might intersect with release site formation.

\section{A Tale of Seeding and Maturation}

Analysis of developmental AZ assembly is dominated by the lossof-function studies in C. elegans and Drosophila larvae, as these, due to their transparent nature, allow for efficient in vivo imaging of their comparatively fast and stereotyped synapse formation program. Rigorous genetic analyses in C. elegans has uncovered major regulatory factors controlling presynaptic assembly. Here, Syd-2 and Liprin- $\alpha /$ Syd-2 superfamily members were found to be important for AZ assembly.

Rigorous genetic analyses in C. elegans over the years have uncovered major regulatory factors controlling presynaptic assembly. Studies began with the identification of Syd-2, a Liprin$\alpha /$ Syd-2 superfamily member, important for synapse assembly at C. elegans synapses. At C. elegans hermaphrodite-specific neuron (HSNL) synapses, Syd-2 gain-of-function studies have shown 
the protein's prime role in operating $A Z$ size and shape, thus promoting the formation of new AZ sites, in the absence of Syd-1 (Dai et al., 2006). Following studies on syd-1 and syd-2 double mutants have revealed that the Syd-1 and Syd-2 can operate together to promote AZ assembly since at these HSNL synapses a substantial loss in SV and AZ proteins were observed (Dai et al., 2006; Patel et al., 2006). In addition, these studies also revealed that the AZ assembly process is also dependent on the expression of an additional AZ protein: ELKS-1, which is required for Syd2 function (Dai et al., 2006; Patel et al., 2006). Loss of ELKS-1 by itself, however, did not cause AZ assembly defects, pointing toward a partial redundancy in the ELKS-1 function, since it acts in concert with Syd-1 and other AZ proteins to positively regulate synapse assembly (Dai et al., 2006). Furthermore, elegant genetic interaction experiments between Syd-1 and Syd-2 have identified downstream players regulating the $\mathrm{AZ}$ assembly process. At first, both syd-1 and syd-2 mutants lose a cohort of synaptic proteins, such as RAB-3, GIT, SAD-1, Unc57/endophilin, and SNN-1/synapsin-1, reaffirming their principal role in recruiting synaptic proteins to the AZ (Patel et al., 2006). Interestingly, these studies also identified a hierarchy between Syd-1, Syd-2 and downstream factors in synapse assembly. Notably, experiments in HSNL synapses show that while Syd-2 overexpression could rescue SV recruitment deficits in the syd-1 mutants, Syd-1 overexpression did not do so in the syd-2 mutant background. Thus, Syd-1 evidently acts upstream of Syd-2 in the AZ assembly line (Dai et al., 2006; Patel et al., 2006).

Complete loss of Syd-2 causes AZs to unravel and become elongated, impairing SV docking and synaptic transmission, thus, implicating Syd-2 as an organizer of AZ proteins at the release site (Stigloher et al., 2011; Kittelmann et al., 2013). In line with these findings, Syd-2, similar to its mammalian counterpart Liprin$\alpha$, colocalizes with other core AZ proteins ELKS-1, Unc10, and Unc13 at C. elegans NMJs, and was found to regulate docking and fusion of SVs at these synapses with these interaction partners (Ackermann et al., 2015). Loss-of-function studies of Unc10 (RIM superfamily member) and Syd-2, for instance, show reduced numbers of docked vesicles at dense projection sites and significantly diminished evoked synaptic transmission (Weimer et al., 2006). In addition, mislocalized SVs were observed docking far away from dense projections in unc10 mutants, and an overall reduction in the size of dense projections was observed at syd-2 mutant synapses (Stigloher et al., 2011; Kittelmann et al., 2013). These observations positioned Syd-2 and Unc10 as prime assembly factors for generating AZs (with their release sites) at C. elegans synapses.

Further investigations of HSNL synapses revealed the involvement of upstream regulators in the process of $\mathrm{AZ}$ assembly. Here, the regulator of synaptogenesis-1 (RSY-1), a synapse disassembly factor, and SYG-1/Neph1 delineate the location of new AZ sites at the HSNL presynaptic terminus. The rys-1 mutants exhibit excessive synapse formation and RSYprotein directly and physically interacts with Syd-1. Syd-1, Syd-2 and ELKS-1 show a high affinity to each other in cell assays, suggesting they form a complex during AZ assembly. RSY1 , is hence, implicated as a negative regulator of this process and potentially acts by weakening the Syd-1-Syd-2 interaction within the AZ assembly complex, by binding to Syd-1 (Patel et al., 2006; Patel and Shen, 2009). Conversely, the SYG-1/Neph1 proteins seemingly specify the position of the presynaptic assembly process by recruiting Syd-1 and Syd-2. These studies when taken together place Syd-1 and Syd-2 as the central players in the regulation of AZ assembly via interactions with ELKS-1, at SYG-1/Neph1-defined sites or pruning of synapses via interaction with RSY-1, the operant negative regulator, at C. elegans synapses.

The C. elegans genetic studies (predominantly at HSNL synapses) have beautifully illustrated the hierarchical interplay involved in AZ seeding and assembly. At Drosophila NMJ synapses, the temporal sequence of seeding and maturing events at developing AZs could be observed directly using intravital imaging techniques, which capitalize on the transparent nature of the larval cuticle. Super-resolution and intravital fluorescence imaging investigations at the larval NMJ have, thus, shed light on the development of glutamatergic synapses in vivo.

Here, assembly of new AZs is mediated by Syd-1/Liprin- $\alpha$ (alias Syd-2) complexes that nucleate the AZ assembly process (Owald et al., 2010). Notably, intravital imaging shows effective accumulation of Liprin- $\alpha$ at the membrane and points of assembly to depend on Syd-1 but not vice versa, a result which corresponds nicely to the genetically retrieved hierarchy worked out at C. elegans synapses (Owald et al., 2010).

Conversely, a disassembly of the AZ scaffold has been described at Drosophila photoreceptor synapses (Sugie et al., 2015). Chronic exposure to high light levels elicits a disassembly of the AZ scaffold here, which might, at least in part, operate in reverse to the assembly sequence of NMJ AZs (Banovic et al., 2010; Owald et al., 2010, 2012; Sugie et al., 2015). However, not all AZ components disassemble completely during prolonged light exposure, as Syd-1 and VGCC al subunit-Cac signals remained rather unaffected in the course of this light triggered disassembly process (Sugie et al., 2015). Liprin- $\alpha$ and RIM-BP were diffusely distributed upon prolonged light exposure as well but did not vanish completely from the $\mathrm{AZ}$, suggesting that they potentially remain in the proximity of the $\mathrm{AZ}$ for quick retrieval, as per need, into dynamically changing AZs (Sugie et al., 2015).

Coordinating synapse assembly requires signaling across the synaptic cleft, which separates pre- from postsynaptic membranes. Trans-synaptic pairs of cell adhesion molecules are obvious candidates for coupling $\mathrm{AZ}$ and PSD assembly and trigger the AZ assembly of nascent AZs. A complex between presynaptic Nrxs and postsynaptic Nlgs can provide the transsynaptic signal required to trigger synapse assembly (Scheiffele et al., 2000; Dean et al., 2003; Missler et al., 2003; Li et al., 2007; Zeng et al., 2007; Choi et al., 2011; Owald et al., 2012). How this trans-synaptic signaling axis integrates with the cytoplasmic assembly machinery is, however, less understood.

Cytoplasmic AZ assembly factor Syd-1 was found to bind the intracellular C-terminus of Drosophila Nrx-1 at Drosophila NMJ synapses, thereby promoting the synaptic clustering and immobilization of Nrx-1. As a result, syd-1 mutants suffer from defective Nlg-1 clustering at postsynaptic sites (Owald et al., 2012). Consistent with the successful formation of this "ménage à trois," where Syd-1/Nrx-1/Nlg-1 are of prime importance, 
postsynaptic glutamate receptor incorporation was affected in syd-1, nrx-1 and nlg- 1 single mutants (Owald et al., 2012). In addition, recent work at NMJ synapses identified an additional layer of $\mathrm{AZ}$ assembly control. Here, the conserved scaffold protein Spinophilin (Spn) binds to Nrx-1, via its PDZ domain, and thus appears to act in competition with Syd-1. As mentioned above, the current data suggest that Syd-1 protein stabilizes Nrx1 at newly forming AZs and promotes the overcoming of an "assembly threshold or hurdle" required to execute the assembly toward a defined mature size (Owald et al., 2012). Absence of Syd-1 reduces the number of successful assembly events and at these remaining events, thus AZs appear overgrown as excess amounts of transported cargoes are delivered into these few sites. By contrast, in the absence of Spn, "excessive seeding" seems to take place, which means that too many AZs form, however, they appear to be too small. One explanation might be that Spn binding to Nrx-1 is incompatible with the process of Nrx-1 binding and recruiting Nlg-1. This would consequently lead to an excess of Nrx-1/Syd-1 complexes in spn mutants, which triggers new assembly at too many $\mathrm{AZ}$ sites, resulting in the distribution of AZ material over too many AZs, and these would, as a result, remain smaller than normal (see Figure 3A, Muhammad et al., 2015).

These early and de novo presynaptic AZ assembly processes may temporally precede postsynaptic scaffold recruitment by immobilizing Nrx-1 and providing more stable Nrx-1 surfaces for recruitment of the postsynaptic scaffold, via Nlg1 molecules, to places of postsynaptic assembly. However, it appears more likely that aspects of pre- and postsynaptic scaffold recruitment occur in a temporally, tightly coupled fashion and that they reciprocally tune each other continuously. Previous intravital imaging studies at NMJ synapses, showed that the assembly of the postsynaptic specializations is also a temporally protracted process, with the GluRIIA subunit containing glutamate receptor complexes preceding the GluRIIB-containing complexes in the in vivo assembly sequence (Rasse et al., 2005; Schmid et al., 2008; Fouquet et al., 2009). As the presynaptic AZ scaffold matures, a visible shift toward DGluRIIB complex incorporation occurs which correlates with increased amounts of BRP in the presynaptic terminus (Schmid et al., 2008) (Figure 3). This "parallel scaling" of PSD scaffold proteins with the presynaptic AZ scaffold implicates cross-talk between the pre- and postsynaptic compartments of an AZ, possibly to promote and regulate sequential assembly processes. Bone morphogenetic protein like ligands (Glass bottom boat) secreted by the muscle, which are then sensed by presynaptic receptors (Wishful Thinking), have been implied in such processes (Aberle et al., 2002; Marqués et al., 2002; McCabe et al., 2003; Keshishian and Kim, 2004).

Mechanisms of regulating the early assembly and seeding of AZ scaffolds are also heavily implicated in the dynamic redistribution of $\mathrm{AZ}$ material between individual $\mathrm{AZ}$ scaffolds. For instance, in general, lower exchange rates of stably incorporated BRP are observed in FRAP experiments between AZs of matured Drosophila NMJ synapses, as compared to BRP exchange rates between immature NMJ AZs (Fouquet et al., 2009). Although, within an AZ BRP mediated increase in release probability has been shown to scale with AZ size (Ehmann et al., 2014). Here, the small GTPase Rab3 controls the dynamic protein composition of the release machinery, through its influence over BRP distribution (Graf et al., 2009; Ehmann et al., 2014).

Such early presynaptic mechanisms are fundamental in dictating the correct sequence of AZ seeding, and subsequent spatiotemporally accurate assembly and scaling of the AZ scaffold, thus exerting an influence on the proper localizations of active release sites and the overall activity of an AZ.

\section{Developmental Maturation of SV-VGCC Coupling During AZ Assembly}

As described above (Chapter: Release sites and the control of SV-VGCC coupling), synaptic transmission operates at different VGCC to $\mathrm{Ca}^{2+}$ sensor distances, with "loose" or microdomain coupling versus "tight" or nanodomain coupling, in existing regimes (Bucurenciu et al., 2008; Schmidt et al., 2013; Vyleta and Jonas, 2014; Wang and Augustine, 2015). Of note are the beautiful biophysical analyses that finds coupling distances to undergo developmental tightening, expressed in changes of release probabilities and short-term plasticity at the Calyx of Held and cortical mammalian synapses (Fedchyshyn and Wang, 2005; Baur et al., 2015). In conjunction, quantitative models have linked coupling distances and VGCCs numbers. This model was built off of data from immature calyx synapses, exhibiting microdomain coupling, which presented 5-6 VGCCs, localized at $\sim 60 \mathrm{~nm}$ from an SV, that were engaged in a single SV fusion event. Once matured and coupled into nanodomains, at the same synapses, only 2-3 VGCCs, positioned $\sim 20 \mathrm{~nm}$ from an SV, were estimated to be involved in a single SV fusion event (Wang et al., 2009). In addition, nanodomain coupling at mature calyxes exhibits a rise in $\mathrm{Ca}^{2+}$ concentrations, which reach $\mathrm{Ca}^{2+}$ sensors, from 35 to $56 \mu \mathrm{M}$ and, hand in hand, a rise is seen in SV release rates from $\sim 600 \mathrm{SVs} / \mathrm{ms}$ to $1000 \mathrm{SVs} / \mathrm{ms}$ at these AZs (Wang et al., 2008). During developmental AZ maturation, such factors and mechanisms of developmental tightening may potentiate the differential spacing of the SVs and VGCCs to defined distances on the presynaptic membrane. However, the molecular mechanisms behind this tightening process have not, as yet, been worked out at the Calyx of Held.

Lack of the filamentous protein Septin5 at Calyx of Held synapses reportedly transforms AZ coupling precociously from an immature microdomain coupled into more matured nanodomain coupling type. Septin5 might establish a physical barrier precluding SV docking/priming at positions too close to VGCCs in the immature state (Yang et al., 2010). However, controlling the relative exact spacing of SVs and VGCCs during developmental and activity-dependent tightening might well require additional proteins, which are likely other $\mathrm{AZ}$ scaffold proteins. (M)Unc13 superfamily proteins are prime molecular candidates to link release site definition to spacing control since they interact with both AZ scaffold factors and SV proteins, (Acuna et al., 2015; Böhme et al., 2016; Wang et al., 2016a; Sakamoto et al., 2018). Isoforms of this family have been shown to not only define release sites locations, at Drosophila NMJ synapses, but also establish differential coupling distances via 


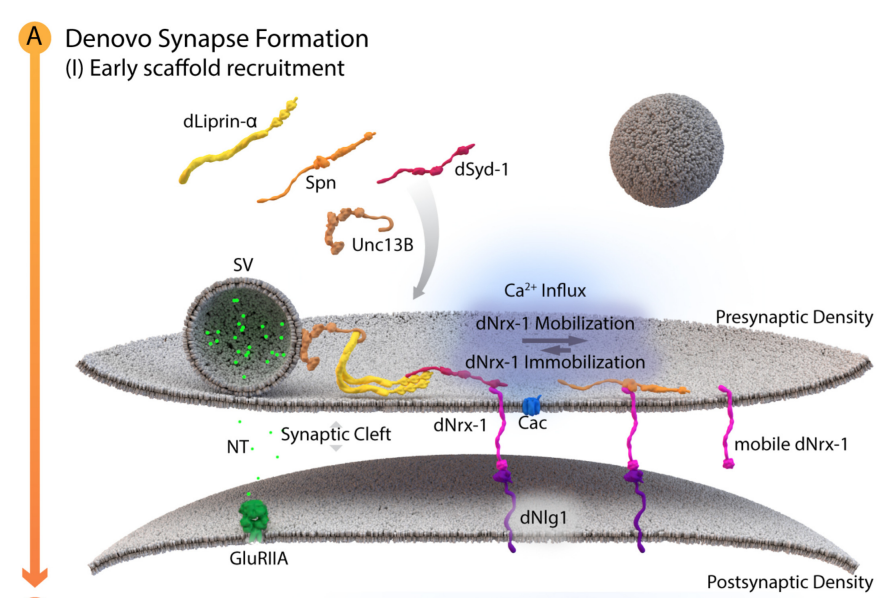

B (II) Late scaffold recruitment

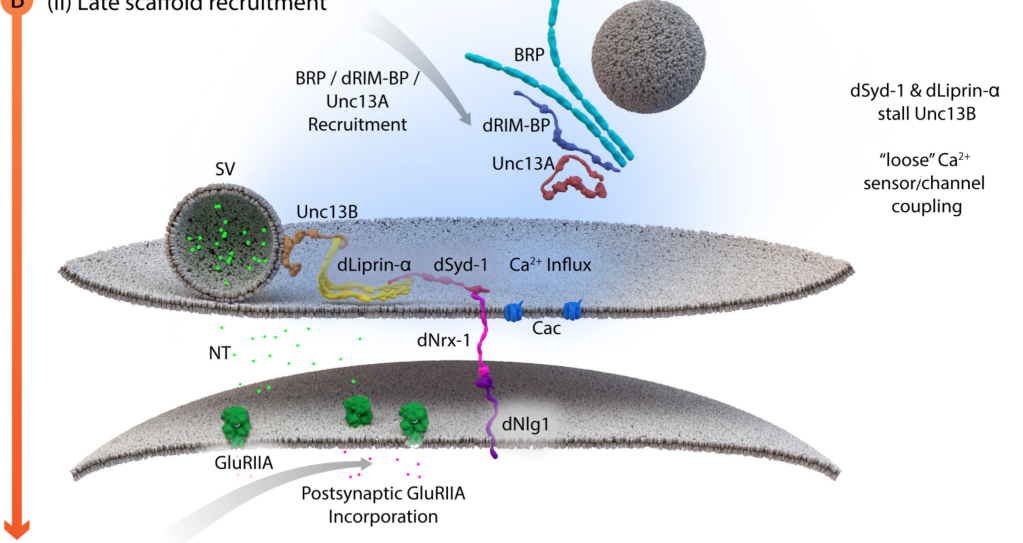

Mature Synapse

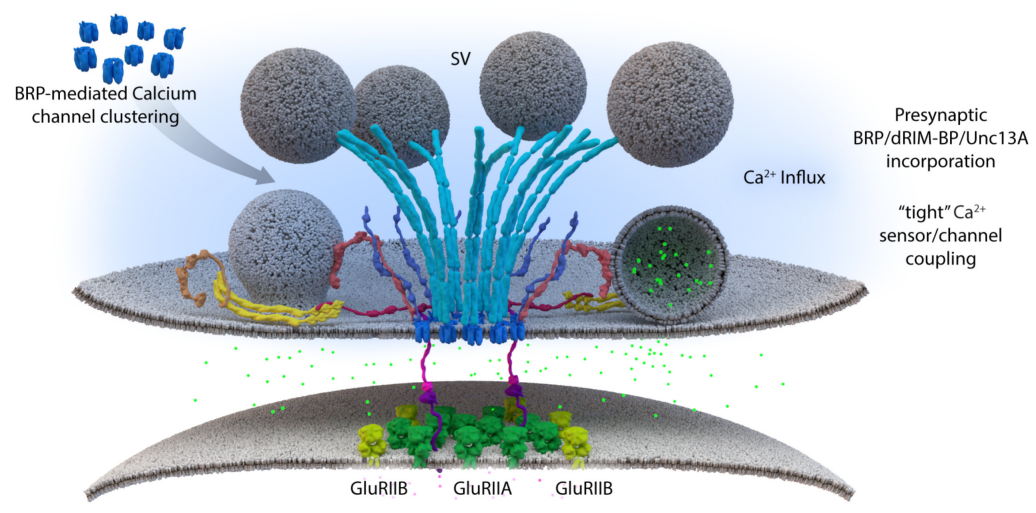

FIGURE 3 | A schematic depicting AZ assembly at Drosophila NMJs. (A) Depicts a schematic of the early AZ scaffold recruitment and assembly. Here, Spn (Spinophilin) acts antagonistically to dSyd-1 (Drosophila Syd-1). Immobile dNrx-1 (Drosophila Neurexin-1) molecules get stabilized at the presynaptic membrane by an interaction with the PDZ domain of dSyd-1. Once dNrx-1 is immobilized at the presynaptic membrane, it forms a bridge with its postsynaptic partner dNIg1 (Drosophila Neuroligin1). In this way, trans-synaptic contact can also initiate pre- and postsynaptic scaffold assembly. Spn competes with dSyd-1 to bind dNrx-1, with its PDZ domain, thus reducing the amount of dNrx-1 available for dSyd-1 binding. This mechanism helps control the seeding and ultimately the number of AZs at a presynaptic bouton. In addition, dLiprin $\alpha$ also binds to dSyd-1 and together these proteins are known to recruit Unc13B to nascent synaptic sites. Unc13B mediated loose coupling of SVs, facilitates SV-fusion and thus NT (neurotransmitter) release into the synaptic cleft. (B) Illustrates a schematic of the late AZ scaffold assembly process. Once a nascent site is established, incorporation of postsynaptic GluRIIA (Glutamate receptor type IIA) on the postsynaptic scaffold is observed, while BRP (Bruchpilot); dRIM-BP (Drosophila RIM-binding protein), and Unc13A proteins are recruited in a second wave of AZ scaffold assembly and center themselves at VGCC localizations. (C) Illustrates the AZ scaffold maturation process at a developing AZ. A stable AZ scaffold forms with BRP and dRIM-BP centered on the VGCCs; here represented by Cac (Drosophila Cacophony). Pre-existing dLiprin $\alpha$ and Unc13B are pushed towards the extremities of the AZ scaffold. The $\mathrm{N}$-terminus of dSyd-1 localizes close to the C-terminal region of BRP. In addition, dSyd-1 still maintains its binding partners the dNrx-1 and dLiprin $\alpha$, thus tethering the early scaffold to the late AZ scaffold structure. BRP mediated VGCC clustering occurs at the presynaptic terminus, while at the postsynapse the incorporation of GluRIIB (Glutamate receptor type IIB) receptors, predominantly occurs outside the GluRIIA receptor field. Unc13A localizes SVs for tight coupling at approximate distances around $70 \mathrm{~nm}$ from the center of the scaffold. 
their distinct N-termini (Böhme et al., 2016; Reddy-Alla et al., 2017). A combination of super-resolution light and EM studies have shown that Unc13A is positioned to dock SVs about $\sim 50-70 \mathrm{~nm}$ from the VGCC cluster center in the middle of the AZ (Böhme et al., 2016). In the same system, with easy accessibility to intravital live imaging, maturation of coupling distances was recently investigated by imaging Unc13 isoforms together with early and late scaffold complex proteins Liprin$\alpha /$ Syd-1 and BRP/RIM-BP, respectively, during the assembly of NMJ AZs. In this study, Unc13B colocalizes with the "early" Liprin- $\alpha /$ Syd-1 scaffold proteins and even its accumulation at AZs sites was found to rely explicitly on the presence of these early scaffold proteins. Consequently, at matured AZs, Unc13B appears clustered at greater distances from VGCCs $(>100 \mathrm{~nm})$, along with the other early AZ players. Conversely, Unc13A was positioned and stabilized in discrete clusters via the BRPRBP scaffold close to presynaptic VGCCs $(<100 \mathrm{~nm})$, during the later stages of the assembly process (Figure 3C) (Böhme et al., 2016). This mechanism integrates a sequence of (M)Unc13 superfamily members into the assembly and maturation of release sites and overall into AZ development. During maturation, the late AZ scaffold incorporates Unc13A near VGCCs; it is hence the Unc13A isoform at mature CAZs that tightens the spatial coupling of release-ready SVs to presynaptic VGCCs and subsequently tunes NT release (Fouquet et al., 2009; Liu et al., 2011; Böhme et al., 2016). These results point to the parallel existence of two functional exocytosis pathways, probably with similar $\mathrm{Ca}^{2+}$ sensing and fusion mechanisms, regulated by the different Unc13 isoforms. The exact spatiotemporal and differential positioning of the two Unc13 isoforms, within the release sites, thus ultimately influences the maturation and function of AZ scaffolds (Böhme et al., 2016) (Figure 4).

In addition, a new study at Drosophila brain synapses shows that the "coupling rules" here are similar as to those found at NMJ synapses (Böhme et al., 2016). Here again, BRP and Syd-1 mediate control of Unc13A and B accumulations, respectively. Loss of either Unc13A or B did not, however, affect BRP or Syd-1 distributions, which implies that these specific scaffold components recruit and position the Unc13 isoforms, not vice versa (Fulterer et al., 2018). Detailed analysis of synapse types of the olfactory circuits of the Drosophila brain have revealed high levels of BRP/Unc13A at their first relay synapses, which, in turn, fostered high release probabilities at these AZs and thus, support the fast but depressing release at these synapses. By comparison, the second relay projection neurons and the interneuron synapses presented high Syd-1/Unc13B levels that consequently promoted "loose" coupling and lower release probabilities at these synapses (Fulterer et al., 2018). This mechanism argues in favor of the presence of tight and loose coupling via (M)Unc13 scaffolds as a design feature to tune and diversify release features across synapses, to adapt them to their specific needs within the relevant circuits.

It will be interesting to see whether a similar logic applies to mammalian synapses as well. Notably, bMunc13-2, a brainspecific mammalian (M)Unc13 superfamily member that also lacks the C2A domain, is recruited by ELKS (homologous to BRP) to $\mathrm{AZ}$ sites (Kawabe et al., 2017). Work on mammalian synapses eludes toward similar trends for coordinating synaptic release. Studies at Calyx of Held synapses demonstrate the "Exclusion Zone" principle, wherein a minimal distance between VGCCs and SVs, in which no SVs can fuse, allow for proper control of release sites (Keller et al., 2015). In a pioneering study, the distinct spatial distribution of Munc13 isoforms at the calyx of Held synapses show Munc13-1 localized to the center of release sites and Munc13-2/3 to peripheral release sites, where Munc13-2 and Munc13-3 together control the slow SV pool contribution to the RRP rather than the fast SV pool and, in concert with Munc131 , regulate release probability and the RRP of SVs at these synapses (Chen et al., 2013). Preferentially loose "microdomain" coupling was observed at immature $\mathrm{AZ}$ sites at these same synapses, while a tight "nanodomain" coupling was more readily observed at mature AZ sites (Wang et al., 2008; Chen et al., 2015; Nakamura et al., 2015). In addition, a recent study on parallel fiber AZs showed that Munc13-3 mediates the regulation of nanodomain coupling at these AZs and regulates Cav2.2 (Ntype) and Cav2.1 (P/Q-type) channel localizations differentially to these AZs (Kusch et al., 2018). These insights reinforce the role of the (M)Unc13 family of proteins, at mammalian CNS and Drosophila NMJ synapses, in defining release sites and the developmental regulation of coupling distances.

Furthermore, work at the C. elegans synapses also displays a differential expression of its two Unc13 isoforms. Unc13L regulates fast release, here, while slow release requires both Unc13L and Unc13S isoforms. Close spacing of the Unc13L isoform to VGCCs was necessary for accelerating NT release and maintaining fast, evoked release at high release probabilities. In an analogous fashion, slow SV release was found to localize mostly outside presynaptic AZ sites (Hu et al., 2013; Zhou et al., 2013).

Taken together, work from mammalian, Drosophila, and C. elegans AZs suggest that (M)Unc13 isoforms follow a sequential developmental assembly sequence, with apparently loose coupling preceding late coupling during $\mathrm{AZ}$ maturation, that is mediated through the differential arrival of $\mathrm{AZ}$ scaffold protein complexes. This points toward the presence of a fundamentally conserved mode of tuning synapse release features, across synapse types, that is regulated by the (M)Unc13 superfamily members.

\section{CONCLUSION AND FUTURE DIRECTIONS}

Decades of work have revealed a conserved subset of AZ scaffold proteins that collectively organize AZs functionally and structurally, and whose relative amounts and isoform spectrum might well be a major means of synapse diversification. Extensive loss-of-function studies of subsets of these core member proteins have revealed at least partial redundancies between AZ scaffold components, and have also provided a fuller appreciation of the multiple, sequential steps within the processes of AZ scaffold assembly and maturation. The AZ scaffold assembly process is based on defined and dynamically regulated protein-protein interactions that employ a conserved set of 


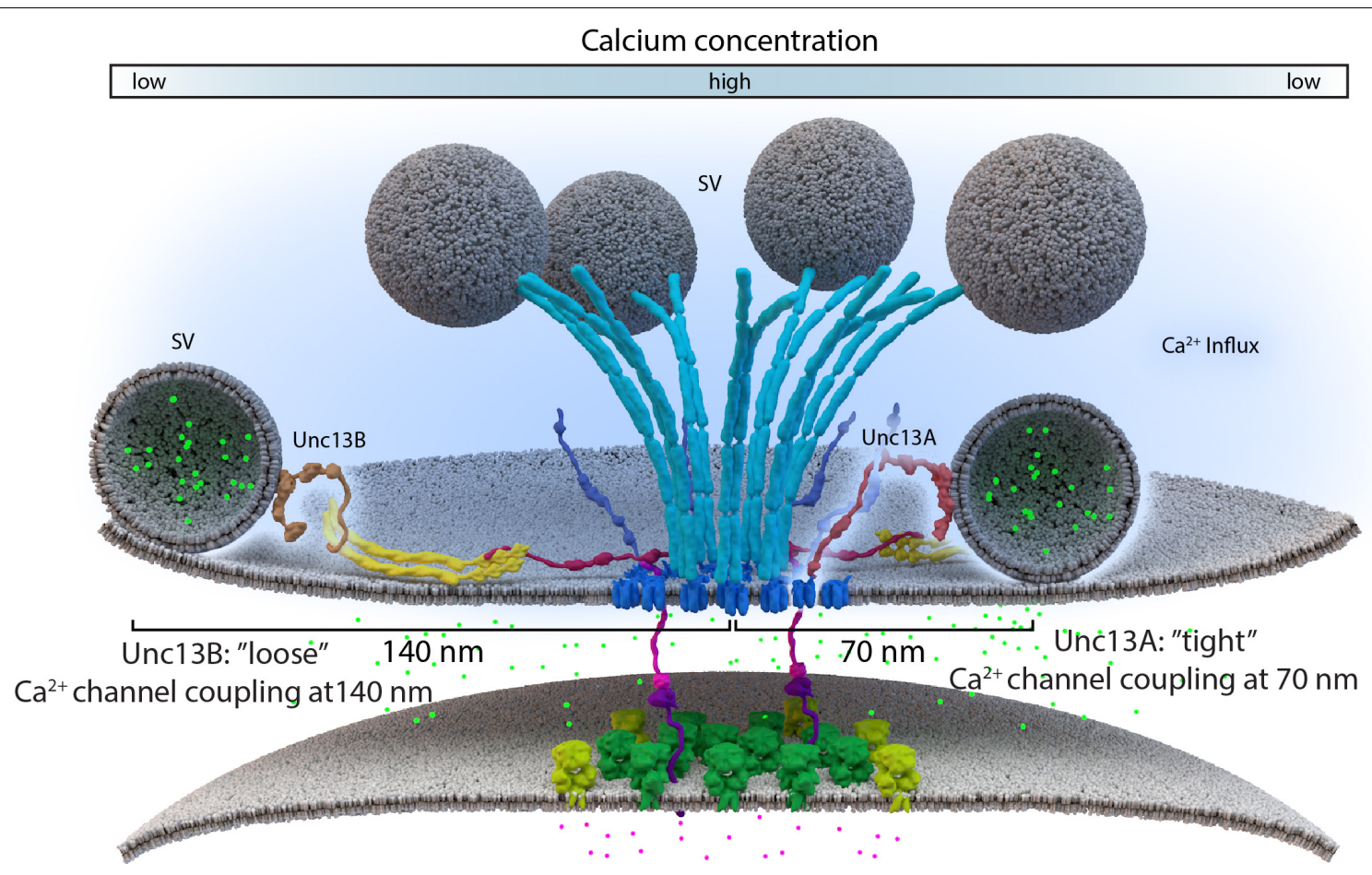

FIGURE 4 | Loose and tight coupling at Drosophila NMJ AZs. A schematic of loose and tight coupling occurring at single NMJ AZs. Loose coupling of SVs, depicted on the left-hand side of the $\mathrm{AZ}$, occurs at low $\mathrm{Ca}^{2+}$ concentrations, at a rough distance of $140 \mathrm{~nm}$ from the $\mathrm{AZ}$ center and localize at Unc13B signals that are positioned $120 \mathrm{~nm}$ from the center. Tight coupling, depicted on the right-hand side of the AZ, occurs near high $\mathrm{Ca}^{2+}$ concentrations, that is typically positioned at a $70 \mathrm{~nm}$ distance from the $\mathrm{AZ}$ center or at Unc13A localizations, which are roughly positioned $50 \mathrm{~nm}$ from the $\mathrm{AZ}$ center.

interaction surfaces including both intra- and intermolecular coiled-coil interactions, as well as SAM and PDZ domain interactions (Südhof, 2012). Bearing in mind that more than just nuanced differences occur at varying synapses to bolster the specific functional needs of individual synapses types, these mechanisms ultimately converge to coordinately regulate release site generation and function within any given AZ.

Research is now the precipice of understanding how AZ scaffolds determine the generation of a new release site and the coordinated sequence of events that promote SV fusion. It could be ascertained that Munc13-1 and Unc13A, both members of the (M)Unc13 family, are the dominant release site-generating molecules (Reddy-Alla et al., 2017; Sakamoto et al., 2018). In addition, the propensity of (M)Unc13 isoforms to differentially localize at AZ sites of Drosophila, C. elegans, and mammalian synapses, to regulate the effective "tight" and "loose" SV coupling to VGCCs, provides a first insight into the developmental and regulatory release site mechanisms on AZ function. (M)Unc13 superfamily members likely exhibit similar functions at different synapses as a result of an evolutionarily conserved design, which may be in place, as a means to adapt to various types of activating stimuli and optimize the speed and reliability of synaptic transmission. Although, the temporal developmental maturation of a release site may be the first big step toward understanding release site modulation on $\mathrm{AZ}$ function, how release site specifications regulate short- and long-term, activity-dependent, plasticity warrants future investigations.

A closer look at the coupling regulated by the (M)Unc13 release site-generating molecules reveals the presence of two scaffold proteins, Syd-1 and BRP, at its core that potentiate loose and tight coupling through (M)Unc13 members at a variety of synapse types in Drosophila (Fulterer et al., 2018). Thus, it would be of imminent interest to discern whether Syd-1 and ELKS/Cast/BRP superfamily members regulated coupling might be a conserved feature in synapses of other model systems. The AZ scaffold-regulated Unc13A and B levels have also been shown to provide a means to vary and tune synaptic release to support functional diversity (Fulterer et al., 2018). Perhaps it would also be of prudent interest to delve further into the relationships between the AZ scaffold and postsynaptic and/or trans-synaptic factors, such as cell adhesion molecules, for example, tenuerins, LRP4 and Elfn1, which may be involved in regulating synaptic plasticity (Hong et al., 2012; Sylwestrak and Ghosh, 2012; Mosca et al., 2017)

In light of these recent advances, the AZ scaffold may very well promote generation, localization, and stabilization of release site slots by exerting influence upon the (M)Unc13 superfamily of proteins and their molecular levels as an evolutionary means to diversify synapses (Fulterer et al., 2018; Nusser, 2018).

The Drosophila NMJ synapses have been particularly successful in applying a combination of genetic modulation with super-resolution microscopy and intravital live imaging. With 
this powerful blend of techniques, recent work at these synapses has been particularly instructive in providing the temporal details of $\mathrm{AZ}$ scaffold assembly and maturation, building upon work from C. elegans, while also providing nanoscopic details of release site coupling that corroborate observations from mammalian synapses. This potent mix of imaging techniques and favorable genetic accessibility available for Drosophila NMJ investigations places a bright future for work in this model system to address a multitude of salient questions emerging now in the subject of release site regulation.

\section{REFERENCES}

Aberle, H., Haghighi, A. P., Fetter, R. D., McCabe, B. D., Magalhães, T. R., and Goodman, C. S. (2002). Wishful thinking encodes a BMP type II receptor that regulates synaptic growth in Drosophila. Neuron 33, 545-558. doi: 10.1016/ S0896-6273(02)00589-5

Ackermann, F., Waites, C. L., and Garner, C. C. (2015). Presynaptic active zones in invertebrates and vertebrates. EMBO Rep. 16, 923-938. doi: 10.15252/embr. 201540434

Acuna, C., Liu, X., Gonzalez, A., and Südhof, T. C. (2015). RIM-BPs mediate tight coupling of action potentials to ca2+-triggered neurotransmitter release. Neuron 87, 1234-1247. doi: 10.1016/J.NEURON.2015.08.027

Acuna, C., Liu, X., and Südhof, T. C. (2016). How to make an active zone: unexpected universal functional redundancy between RIMs and RIM-BPs. Neuron 91, 792-807. doi: 10.1016/J.NEURON.2016.07.042

Alvarez-Baron, E., Michel, K., Mittelstaedt, T., Opitz, T., Schmitz, F., Beck, H., et al. (2013). RIM3 and RIM4 are key regulators of neuronal arborization. J. Neurosci. 33, 824-839. doi: 10.1523/JNEUROSCI.2229-12.2013

Arai, I., and Jonas, P. (2014). Nanodomain coupling explains $\mathrm{Ca}^{2+}$ independence of transmitter release time course at a fast central synapse. eLife 3:e04057. doi: 10.7554/eLife.04057

Auger, C., and Marty, A. (2000). Quantal currents at single-site central synapses. J. Physiol. 526(Pt 1), 3-11. doi: 10.1111/J.1469-7793.2000.T01-3-00003.X

Banovic, D., Khorramshahi, O., Owald, D., Wichmann, C., Riedt, T., Fouquet, W., et al. (2010). Drosophila neuroligin 1 promotes growth and postsynaptic differentiation at glutamatergic neuromuscular junctions. Neuron 66, 724-738. doi: 10.1016/J.NEURON.2010.05.020

Basu, J., Betz, A., Brose, N., and Rosenmund, C. (2007). Munc13-1 C1 domain activation lowers the energy barrier for synaptic vesicle fusion. J. Neurosci. 27, 1200-1210. doi: 10.1523/JNEUROSCI.4908-06.2007

Basu, J., Shen, N., Dulubova, I., Lu, J., Guan, R., Guryev, O., et al. (2005). A minimal domain responsible for munc13 activity. Nat. Struct. Mol. Biol. 12, 1017-1018. doi: $10.1038 / \mathrm{nsmb} 1001$

Baur, D., Bornschein, G., Althof, D., Watanabe, M., Kulik, A., Eilers, J., et al. (2015). Developmental tightening of cerebellar cortical synaptic influx-release coupling. J. Neurosci.? 35, 1858-1871. doi: 10.1523/JNEUROSCI.2900-14.2015

Bekkers, J. M., Richerson, G. B., and Stevens, C. F. (1990). Origin of variability in quantal size in cultured hippocampal neurons and hippocampal slices. Proc. Natl. Acad. Sci. U.S.A. 87, 5359-5362. doi: 10.1073/pnas.87.14.5359

Böhme, M. A., Beis, C., Reddy-Alla, S., Reynolds, E., Mampell, M. M., Grasskamp, A. T., et al. (2016). Articles active zone scaffolds differentially accumulate Unc13 isoforms to tune $\mathrm{Ca}^{2+}$ channel - vesicle coupling. Nat. Neurosci. 19, 1311-1320. doi: $10.1038 / \mathrm{nn} .4364$

Borst, J. G., and Soria van Hoeve, J. (2012). The calyx of held synapse: from model synapse to auditory relay. Annu. Rev. Physiol. 74, 199-224. doi: 10.1146/ annurev-physiol-020911-153236

Brumell, J. H., Volchuk, A., Sengelov, H., Borregaard, N., Cieutat, A. M., Bainton, D. F., et al. (1995). Subcellular distribution of docking/fusion proteins in neutrophils, secretory cells with multiple exocytic compartments. J. Immunol. 155, 5750-5759. doi: 10.4049/jimmunol.180.10.6786

Bucurenciu, I., Kulik, A., Schwaller, B., Frotscher, M., and Jonas, P. (2008). Nanodomain coupling between $\mathrm{Ca}^{2+}$ channels and $\mathrm{Ca}^{2+}$ sensors promotes fast

\section{AUTHOR CONTRIBUTIONS}

TG and SS both contributed equally to the writing and editing of this piece.

\section{ACKNOWLEDGMENTS}

The support of the Deutsche Forschungsgemeinschaft (DFG) research units 'TRR186' (grant no: 0440041203) and 'SFB 958/A03' (grant no: 0421961207), was gratefully acknowledged.

and efficient transmitter release at a cortical GABAergic synapse. Neuron 57, 536-545. doi: 10.1016/J.NEURON.2007.12.026

Byczkowicz, N., Ritzau-Jost, A., Delvendahl, I., and Hallermann, S. (2018). How to maintain active zone integrity during high-frequency transmission. Neurosci. Res. 127, 61-69. doi: 10.1016/J.NEURES.2017.10.013

Chabrol, F. P., Arenz, A., Wiechert, M. T., Margrie, T. W., and DiGregorio, D. A. (2015). Synaptic diversity enables temporal coding of coincident multisensory inputs in single neurons. Nat. Neurosci. 18, 718-727. doi: 10.1038/nn. 3974

Chen, Z., Cooper, B., Kalla, S., Varoqueaux, F., and Young, S. M. (2013). The munc13 proteins differentially regulate readily releasable pool dynamics and calcium-dependent recovery at a central synapse. J. Neurosci. 33, 8336-8351. doi: 10.1523/JNEUROSCI.5128-12.2013

Chen, Z., Das, B., Nakamura, Y., DiGregorio, D. A., and Young, S. M. (2015). Ca ${ }^{2+}$ channel to synaptic vesicle distance accounts for the readily releasable pool kinetics at a functionally mature auditory synapse. J. Neurosci. 35, 2083-2100. doi: 10.1523/JNEUROSCI.2753-14.2015

Choi, Y. B., Li, H. L., Kassabov, S. R., Jin, I., Puthanveettil, S. V., Karl, K. A., et al. (2011). Neurexin-neuroligin transsynaptic interaction mediates learningrelated synaptic remodeling and long-term facilitation in aplysia. Neuron 70, 468-481. doi: 10.1016/j.neuron.2011.03.020

Couteaux, R., and Pécot-Dechavassine, M. (1970). Synaptic vesicles and pouches at the level of \& quot; active zones \& quot; of the neuromuscular junction. C. $R$. Acad. Sci. Hebd. Seances Acad. Sci. D 271, 2346-2349.

Crozat, K., Hoebe, K., Ugolini, S., Hong, N. A., Janssen, E., Rutschmann, S., et al. (2007). Jinx, an MCMV susceptibility phenotype caused by disruption of unc13d: a mouse model of type 3 familial hemophagocytic lymphohistiocytosis. J. Exp. Med. 204, 853-863. doi: 10.1084/jem.20062447

Dai, Y., Taru, H., Deken, S. L., Grill, B., Ackley, B., Nonet, M. L., et al. (2006). SYD-2 liprin- $\alpha$ organizes presynaptic active zone formation through ELKS. Nat. Neurosci. 9, 1479-1487. doi: 10.1038/nn1808

De Robertis, E. D., and Bennett, H. S. (1955). Some features of the submicroscopic morphology of synapses in frog and earthworm. J. Biophys. Biochem. Cytol. 1, 47-58. doi: 10.1083/jcb.1.1.47

Dean, C., Scholl, F. G., Choih, J., DeMaria, S., Berger, J., Isacoff, E., et al. (2003). Neurexin mediates the assembly of presynaptic terminals. Nat. Neurosci. 6, 708-716. doi: 10.1038/nn1074

Deguchi-Tawarada, M., Inoue, E., Takao-Rikitsu, E., Inoue, M., Kitajima, I., Ohtsuka, T., et al. (2006). Active zone protein cast is a component of conventional and ribbon synapses in mouse retina. J. Comp. Neurol. 495, 480-496. doi: 10.1002/cne.20893

Deguchi-Tawarada, M., Inoue, E., Takao-Rikitsu, E., Inoue, M., Ohtsuka, T., and Takai, Y. (2004). CAST2: identification and characterization of a protein structurally related to the presynaptic cytomatrix protein CAST. Genes Cells 9 , 15-23. doi: 10.1111/j.1356-9597.2004.00697

Deken, S. L., Vincent, R., Hadwiger, G., Liu, Q., Wang, Z. W., and Nonet, M. L. (2005). Redundant localization mechanisms of RIM and ELKS in caenorhabditis elegans. J. Neurosci. 25, 5975-5983. doi: 10.1523/JNEUROSCI. 0804-05.2005

Del Castillo, J. D., and Engbaek, L. (1954). The nature of the neuromuscular block produced by magnesium. J. Physiol. 124, 370-384. doi: 10.1113/jphysiol.1954. sp005114 
Delvendahl, I., and Hallermann, S. (2016). the cerebellar mossy fiber synapse as a model for high-frequency transmission in the mammalian CNS. Trends Neurosci. 39, 722-737. doi: 10.1016/J.TINS.2016.09.006

Deng, L., Kaeser, P. S., Xu, W., and Südhof, T. C. (2011). RIM proteins activate vesicle priming by reversing autoinhibitory homodimerization of Munc13. Neuron 69, 317-331. doi: 10.1016/j.neuron.2011.01.005

Dick, O., Tom Dieck, S., Altrock, W. D., Ammermüller, J., Weiler, R., Garner, C. C., et al. (2003). The presynaptic active zone protein bassoon is essential for photoreceptor ribbon synapse formation in the retina. Neuron 37, 775-786. doi: 10.1016/S0896-6273(03)00086-2

Dudenhöffer-Pfeifer, M., Schirra, C., Pattu, V., Halimani, M., Maier-Peuschel, M., Marshall, M. R., et al. (2013). Different munc13 isoforms function as priming factors in lytic granule release from murine Cytotoxic T lymphocytes. Traffic 14, 798-809. doi: $10.1111 /$ tra. 12074

Dulubova, I., Lou, X., Lu, J., Huryeva, I., Alam, A., Schneggenburger, R., et al. (2005). A Munc13/RIM/Rab3 tripartite complex: from priming to plasticity? EMBO J. 24, 2839-2850. doi: 10.1038/sj.emboj.7600753

Eggermann, E., Bucurenciu, I., Goswami, S. P., and Jonas, P. (2012). Nanodomain coupling between $\mathrm{Ca}^{2+}$ channels and sensors of exocytosis at fast mammalian synapses. Nat. Rev. Neurosci. 13, 7-21. doi: 10.1038/nrn3125

Ehmann, N., Sauer, M., and Kittel, R. J. (2015). Super-resolution microscopy of the synaptic active zone. Front. Cell. Neurosci. 9:7. doi: 10.3389/fncel.2015.00007

Ehmann, N., van de Linde, S., Alon, A., Ljaschenko, D., Keung, X. Z., Holm, T., et al. (2014). Quantitative super-resolution imaging of bruchpilot distinguishes active zone states. Nat. Commun. 5:4650. doi: 10.1038/ncomms5650

Fatt, P., and Katz, B. (1952). Spontaneous subthreshold activity at motor nerve endings. J. Physiol. 117, 109-128.

Fedchyshyn, M. J., and Wang, L. Y. (2005). Developmental transformation of the release modality at the Calyx of held synapse. J. Neurosci. 25, 4131-4140. doi: 10.1523/JNEUROSCI.0350-05.2005

Fouquet, W., Owald, D., Wichmann, C., Mertel, S., Depner, H., Dyba, M., et al. (2009). Maturation of active zone assembly by drosophila bruchpilot. J. Cell Biol. 186, 129-145. doi: $10.1083 /$ jcb.200812150

Frank, T., Rutherford, M. A., Strenzke, N., Neef, A., Pangršič, T., Khimich, D., et al. (2010). Bassoon and the synaptic ribbon organize $\mathrm{Ca}^{2+}$ channels and vesicles to add release sites and promote refilling. Neuron $68,724-738$. doi: 10.1016/j.neuron.2010.10.027

Fulterer, A., Andlauer, T. F. M., Walter, A. M., Nagel, K. I., and Sigrist, S. J. (2018). Active zone scaffold protein ratios tune functional diversity across brain synapses. Cell Rep. 23, 1259-1247. doi: 10.1016/j.celrep.2018.03.126

Gaffield, M. A., Tabares, L., and Betz, W. J. (2009). The spatial pattern of exocytosis and post-exocytic mobility of synaptophluorin in mouse motor nerve terminals. J. Physiol. 587, 1187-1200. doi: 10.1113/jphysiol.2008.166728

Gjorgjieva, J., Evers, J. F., and Eglen, S. J. (2016). Homeostatic activity-dependent tuning of recurrent networks for robust propagation of activity. J. Neurosci. 36, 3722-3734. doi: 10.1523/JNEUROSCI.2511-15.2016

Graf, E. R., Daniels, R. W., Burgess, R. W., Schwarz, T. L., and DiAntonio, A. (2009). Rab3 dynamically controls protein composition at active zones. Neuron 64, 663-677. doi: 10.1016/j.neuron.2009.11.002

Graf, E. R., Valakh, V., Wright, C. M., Wu, C., Liu, Z., Zhang, Y. Q., et al. (2012). RIM promotes calcium channel accumulation at active zones of the Drosophila neuromuscular junction. J. Neurosci. 32, 16586-16596. doi: 10.1523/ JNEUROSCI.0965-12.2012

Grauel, M. K., Maglione, M., Reddy-Alla, S., Willmes, C. G., and Brockmann, M. M. (2016). RIM-binding protein 2 regulates release probability by finetuning calcium channel localization at murine hippocampal synapses. Proc. Natl. Acad. Sci. U.S.A 113, 11615-11620. doi: 10.1073/pnas.1605256113

Gundelfinger, E. D., and Fejtova, A. (2012). Molecular organization and plasticity of the cytomatrix at the active zone. Curr. Opin. Neurobiol. 22, 423-430. doi: 10.1016/j.conb.2011.10.005

Gundelfinger, E. D., Reissner, C., and Garner, C. C. (2016). Role of bassoon and piccolo in assembly and molecular organization of the active zone. Front. Synaptic Neurosci. 7:19. doi: 10.3389/fnsyn.2015.00019

Hallam, S. J., Goncharov, A., McEwen, J., Baran, R., and Jin, Y. (2002). SYD1, a presynaptic protein with PDZ, C2 and RhoGAP-like domains, specifies axon identity in C. Elegans. Nat. Neurosci. 5, 1137-1146. doi: 10.1038/ nn959
Hallermann, S., Kittel, R. J., Wichmann, C., Weyhersmüller, A., Fouquet, W., Mertel, S., et al. (2010). Naked dense bodies provoke depression. J. Neurosci. 30, 14340-14345. doi: 10.1523/JNEUROSCI.2495-10.2010

Hamanaka, Y., and Meinertzhagen, I. A. (2010). Immunocytochemical localization of synaptic proteins to photoreceptor synapses of Drosophila melanogaster. J. Comp. Neurol. 518, 1133-1155. doi: 10.1002/cne.22268

Han, Y., Kaeser, P. S., Südhof, T. C., and Schneggenburger, R. (2011). RIM determines $\mathrm{Ca}^{2+}$ channel density and vesicle docking at the presynaptic active zone. Neuron 69, 304-316. doi: 10.1016/j.neuron.2010.12.014

Harlow, M. L., Ress, D., Stoschek, A., Marshall, R. M., and McMahan, U. J. (2001). The architecture of active zone material at the frog's neuromuscular junction. Nature 409, 479-484. doi: 10.1038/35054000

Held, R. G., Liu, C., and Kaeser, P. S. (2016). ELKS controls the pool of readily releasable vesicles at excitatory synapses through its $\mathrm{n}$-terminal coiled-coil domains. eLife 5:e14862. doi: 10.7554/eLife.14862

Hennig, M. H. (2013). Theoretical models of synaptic short term plasticity. Front. Comput. Neurosci. 7:45. doi: 10.3389/fncom.2013.00045

Heuser, J. E., Reese, T. S., Dennis, M. J., Jan, Y., Jan, L., and Evans, L. (1979). Synaptic vesicle exocytosis captured by quick freezing and correlated with quantal transmitter release. J. Cell Biol. 81, 275-300. doi: 10.1083/jcb.81.2.275

Hibino, H., Pironkova, R., Onwumere, O., Vologodskaia, M., Hudspeth, A. J., and Lesage, F. (2002). RIM binding proteins (RBPs) couple rab3-interacting molecules (RIMs) to voltage-gated $\mathrm{Ca}^{2+}$ channels. Neuron 34, 411-423. doi: 10.1016/S0896-6273(02)00667-0

Hida, y., and Ohtsuka, t. (2010). cast and elks proteins: structural and functional determinants of the presynaptic active zone. J. Biochem. 148, 131-137. doi: $10.1093 / \mathrm{jb} / \mathrm{mvq} 065$

Hong, W., Mosca, T. J., and Luo, L. (2012). Teneurins instruct synaptic partner matching in an olfactory map. Nature 484, 201-207. doi: 10.1038/nature10926

Hou, J., Tamura, T., and Kidokoro, Y. (2008). Delayed synaptic transmission in drosophila cacophonynull embryos. J. Neurophysiol. 100, 2833-2842. doi: $10.1152 /$ jn. 90342.2008

Hu, Z., Tong, X. J., and Kaplan, J. M. (2013). UNC-13L, UNC-13S, and tomosyn form a protein code for fast and slow neurotransmitter release in caenorhabditis elegans. eLife 2:e00967. doi: 10.7554/eLife.00967

Imig, C., Min, S. W., Krinner, S., Arancillo, M., Rosenmund, C., Südhof, T. C., et al. (2014). The morphological and molecular nature of synaptic vesicle priming at presynaptic active zones. Neuron 84, 416-431. doi: 10.1016/J.NEURON.2014. 10.009

Jackman, S. L., and Regehr, W. G. (2017). The mechanisms and functions of synaptic facilitation. Neuron 94, 447-464. doi: 10.1016/j.neuron.2017.02.047

Jahn, R., and Fasshauer, D. (2012). Molecular machines governing exocytosis of synaptic vesicles. Nature 490, 201-207. doi: 10.1038/nature11320

Jiao, W., Masich, S., Franzén, O., and Shupliakov, O. (2010). Two pools of vesicles associated with the presynaptic cytosolic projection in Drosophila neuromuscular junctions. J. Struct. Biol. 172, 389-394. doi: 10.1016/J.JSB.2010. 07.007

Kaeser, P. S. (2011). Pushing synaptic vesicles over the RIM. Cell. Logist. 1, 106-110. doi: 10.4161/cl.1.3.16429

Kaeser, P. S., Deng, L., Chávez, A. E., Liu, X., Castillo, P. E., and Südhof, T. C. (2009). ELKS2 $\alpha /$ CAST deletion selectively increases neurotransmitter release at inhibitory synapses. Neuron 64, 227-239. doi: 10.1016/j.neuron.2009. 09.019

Kaeser, P. S., Deng, L., Wang, Y., Dulubova, I., Liu, X., Rizo, J., et al. (2011). RIM proteins tether $\mathrm{Ca}^{2+}$ channels to presynaptic active zones via a direct PDZ-domain interaction. Cell 144, 282-295. doi: 10.1016/J.CELL.2010.12.029

Kaeser, P. S., and Held, R. G. (2018). ELKS active zone proteins as multitasking scaffolds for secretion. Open Biol. 8:170258. doi: 10.1098/rsob.170258

Kaeser, P. S., and Regehr, W. G. (2017). The readily releasable pool of synaptic vesicles. Curr. Opin. Neurobiol. 43, 63-70. doi: 10.1016/J.CONB.2016.12.012

Katz, B. (1971). Quantal mechanism of neural transmitter release. Science 173, 123-126. doi: $10.1126 /$ science.173.3992.123

Kaufmann, N., DeProto, J., Ranjan, R., Wan, H., and Van Vactor, D. (2002). Drosophila liprin-alpha and the receptor phosphatase dlar control synapse morphogenesis. Neuron 34, 27-38. doi: 10.1016/S0896-6273(02)00643-8

Kawabe, H., Mitkovski, M., Kaeser, P. S., Hirrlinger, J., Opazo, F., Nestvogel, D., et al. (2017). elks1 localizes the synaptic vesicle priming protein BMunc13-2 to 
a specific subset of active zones. J. Cell Biol. 216, 1143-1161. doi: 10.1083/jcb. 201606086

Kawasaki, F. (2004). Active zone localization of presynaptic calcium channels encoded by the cacophony locus of Drosophila. J. Neurosci. 24, 282-285. doi: 10.1523/JNEUROSCI.3553-03.2004

Kawasaki, F., Collins, S. C., and Ordway, R. W. (2002). Synaptic calcium-channel function in Drosophila: analysis and transformation rescue of temperaturesensitive paralytic and lethal mutations of cacophony. J. Neurosci. 22, 58565864. doi: 10.1523/JNEUROSCI.22-14-05856.2002

Keller, D., Babai, N., Kochubey, O., Han, Y., Markram, H., Schürmann, F., et al. (2015). An exclusion zone for $\mathrm{Ca}^{2+}$ channels around docked vesicles explains release control by multiple channels at a CNS synapse. PLoS Comput. Biol. 11:e1004253. doi: 10.1371/journal.pcbi.1004253

Keshishian, H., and Kim, Y. S. (2004). Orchestrating development and function: retrograde BMP signaling in the Drosophila nervous system. Trends Neurosci. 27, 143-147. doi: 10.1016/J.TINS.2004.01.004

Khimich, D., Nouvian, R., Pujol, R., Tom Dieck, S., Egner, A., Gundelfinger, E. D., et al. (2005). Synchronous auditory signalling. Nature 434, 889-894. doi: $10.1038 /$ nature 03418

Kittel, R. J., Hallermann, S., Thomsen, S., Wichmann, C., Sigrist, S. J., Heckmann, M., et al. (2006). Active zone assembly and synaptic release. Biochem. Soc. Trans. 34(Pt 5), 939-941. doi: 10.1042/BST0340939

Kittelmann, M., Hegermann, J., Goncharov, A., Taru, H., Ellisman, M. H., Richmond, J. E., et al. (2013). Liprin- $\alpha$ /SYD-2 determines the size of dense projections in presynaptic active zones in C. Elegans. J. Cell Biol. 203, 849-863. doi: $10.1083 /$ jcb. 201302022

Ko, J., Na, M., Kim, S., Lee, J. R., and Kim, E. (2003). Interaction of the ERC family of RIM-binding proteins with the liprin- $\alpha$ family of multidomain proteins. J. Biol. Chem. 278, 42377-42385. doi: 10.1074/jbc.M307561200

Koch, H., Hofmann, K., and Brose, N. (2000). Definition of Munc13-homologydomains and characterization of a novel ubiquitously expressed munc13 isoform. Biochem. J. 349(Pt 1), 247-253. doi: 10.1042/bj3490247

Kusch, V., Bornschein, G., Loreth, D., Bank, J., Jordan, J., Baur, D., et al. (2018). Munc13-3 is required for the developmental localization of $\mathrm{Ca}^{2+}$ channels to active zones and the nanopositioning of Cav2.1 near release sensors. Cell Rep. 22, 1965-1973. doi: 10.1016/J.CELREP.2018.02.010

Li, J., Ashley, J., Budnik, V., and Bhat, M. A. (2007). Crucial role of drosophila neurexin in proper active zone apposition to postsynaptic densities, synaptic growth, and synaptic transmission. Neuron 55, 741-755. doi: 10.1016/J. NEURON.2007.08.002

Lipstein, N., Sakaba, T., Cooper, B. H., Lin, K. H., Strenzke, N., Ashery, U., et al. (2013). Dynamic control of synaptic vesicle replenishment and shortterm plasticity by $\mathrm{Ca}^{2+}$-calmodulin-Munc13-1 signaling. Neuron 79, 82-96. doi: 10.1016/j.neuron.2013.05.011

Liu, C., Bickford, L. S., Held, R. G., Nyitrai, H., Südhof, T. C., and Kaeser, P. S. (2014). The active zone protein family ELKS supports $\mathrm{Ca}^{2+}$ influx at nerve terminals of inhibitory hippocampal neurons. J. Neurosci. 34, 12289-12303. doi: 10.1523/JNEUROSCI.0999-14.2014

Liu, G., and Tsien, R. W. (1995). Properties of synaptic transmission at single hippocampal synaptic boutons. Nature 375, 404-408. doi: 10.1038/375404a0

Liu, K. S., Siebert, M., Mertel, S., Knoche, E., Wegener, S., Wichmann, C., et al. (2011). RIM-binding protein, a central part of the active zone, is essential for neurotransmitter release. Science 334, 1565-1569. doi: 10.1126/science.1212991

Lu, H. C., Butts, D. A., Kaeser, P. S., She, W. C., Janz, R., and Crair, M. C. (2006). Role of efficient neurotransmitter release in barrel map development. J. Neurosci. 26, 2692-2703. doi: 10.1523/JNEUROSCI.3956-05.2006

Ma, C., Li, W., Xu, Y., and Rizo, J. (2011). Munc13 mediates the transition from the closed syntaxin-Munc18 complex to the SNARE complex. Nat. Struct. Mol. Biol. 18, 542-549. doi: 10.1038/nsmb.2047

Maglione, M., and Sigrist, S. J. (2013). Seeing the forest tree by tree? superresolution light microscopy meets the neurosciences. Nat. Neurosci. 16, 790797. doi: 10.1038/nn.3403

Man, K. N., Imig, C., Walter, A. M., Pinheiro, P. S., Stevens, D. R., Rettig, J., et al. (2015). Identification of a Munc13-SENSITIVE STEp in chromaffin cell large dense-core vesicle exocytosis. eLife 4:e10635. doi: 10.7554/eLife. 10635

Marqués, G., Bao, H., Haerry, T. E., Shimell, M. J., Duchek, P., Zhang, B., et al. (2002). The Drosophila BMP type II receptor wishful thinking regulates neuromuscular synapse morphology and function. Neuron 33, 529-543. doi: 10.1016/S0896-6273(02)00595-0

Matkovic, T., Siebert, M., Knoche, E., Depner, H., Mertel, S., Owald, D., et al. (2013). The bruchpilot cytomatrix determines the size of the readily releasable pool of synaptic vesicles. J. Cell Biol. 202, 667-683. doi: 10.1083/jcb.201301072

McCabe, B. D., Marqués, G., Haghighi, A. P., Fetter, R. D., Crotty, M. L., Haerry, T. E., et al. (2003). The BMP homolog Gbb provides a retrograde signal that regulates synaptic growth at the drosophila neuromuscular junction. Neuron 39, 241-254. doi: 10.1016/S0896-6273(03)00426-4

Meinrenken, C. J., Borst, J. G., and Sakmann, B. (2002). Calcium secretion coupling at calyx of held governed by nonuniform channel-vesicle topography. J. Neurosci. 22, 1648-1667. doi: 10.1523/JNEUROSCI.22-05-01648.2002

Melom, J. E., Akbergenova, Y., Gavornik, J. P., and Littleton, J. T. (2013). Spontaneous and evoked release are independently regulated at individual active zones. J. Neurosci. 33, 17253-17263. doi: 10.1523/JNEUROSCI.3334-13. 2013

Midorikawa, M., Okamoto, Y., and Sakaba, T. (2014). Developmental changes in $\mathrm{Ca}^{2+}$ channel subtypes regulating endocytosis at the calyx of held. J. Physiol. 592, 3495-3510. doi: 10.1113/jphysiol.2014.273243

Miki, T., Kaufmann, W. A., Malagon, G., Gomez, L., Tabuchi, K., Watanabe, M., et al. (2017). Numbers of presynaptic $\mathrm{Ca}^{2+}$ channel clusters match those of functionally defined vesicular docking sites in single central synapses. Proc. Natl. Acad. Sci. U.S.A. 114, E5246-E5255. doi: 10.1073/pnas.1704470114

Miki, T., Malagon, G., Pulido, C., Llano, I., Neher, E., Marty, A., et al. (2016). Actinand myosin-dependent vesicle loading of article actin- and myosin-dependent vesicle loading of presynaptic docking sites prior to exocytosis. Neuron 91, 808-823. doi: 10.1016/j.neuron.2016.07.033

Missler, M., Zhang, W., Rohlmann, A., Kattenstroth, G., Hammer, R. E., Gottmann, K., et al. (2003). $\alpha$-Neurexins couple $\mathrm{Ca}^{2+}$ channels to synaptic vesicle exocytosis. Nature 423, 939-948. doi: 10.1038/nature01755

Mosca, T. J., Luginbuhl, D. J., Wang, I. E., and Luo, L. (2017). Presynaptic lrp4 promotes synapse number and function of excitatory CNS neurons. eLife 6:e27347. doi: 10.7554/eLife.27347

Muhammad, K., Reddy-Alla, S., Driller, J. H., Schreiner, D., Rey, U., Böhme, M. A., et al. (2015). Presynaptic spinophilin tunes neurexin signalling to control active zone architecture and function. Nat. Commun. 6:8362. doi: 10.1038/ ncomms 9362

Müller, M., Liu, K. S., Sigrist, S. J., and Davis, G. W. (2012). RIM Controls homeostatic plasticity through modulation of the readily-releasable vesicle pool. J. Neurosci. 32, 16574-16585. doi: 10.1523/JNEUROSCI.0981-12.2012

Nakamura, Y., Harada, H., Kamasawa, N., Matsui, K., Rothman, J. S., Shigemoto, R., et al. (2015). Nanoscale distribution of presynaptic $\mathrm{Ca}^{2+}$ channels and its impact on vesicular release during development. Neuron 85, 145-158. doi: 10.1016/j.neuron.2014.11.019

Nakata, T., Yokota, T., Emi, M., and Minami, S. (2002). Differential expression of multiple isoforms of theELKS MRNAs involved in a papillary thyroid carcinoma. Genes Chromosomes Cancer 35, 30-37. doi: 10.1002/gcc.10095

Neher, E. (2010). What is rate-limiting during sustained synaptic activity: vesicle supply or the availability of release sites. Front. Synaptic Neurosci. 2:144. doi: $10.3389 /$ fnsyn.2010.00144

Neher, E. (2015). Neuron perspective merits and limitations of vesicle pool models in view of heterogeneous populations of synaptic vesicles. Neuron $87,1131-$ 1142. doi: 10.1016/j.neuron.2015.08.038

Neher, E., and Sakaba, T. (2008). Multiple roles of calcium ions in the regulation of neurotransmitter release. Neuron 59, 861-872. doi: 10.1016/j.neuron.2008. 08.019

Nusser, Z. (2018). Creating diverse synapses from the same molecules. Curr. Opin. Neurobiol. 51, 8-15. doi: 10.1016/J.CONB.2018.01.001

Ohtsuka, T., Takao-Rikitsu, E., Inoue, E., Inoue, M., Takeuchi, M., Matsubara, K., et al. (2002). Cast: a novel protein of the cytomatrix at the active zone of synapses that forms a ternary complex with RIM1 and Munc13-1. J. Cell Biol. 158, 577-590. doi: 10.1083/jcb.200202083

O’Rourke, N. A., Weiler, N. C., Micheva, K. D., and Smith, S. J. (2012). Deep molecular diversity of mammalian synapses: why it matters and how to measure it. Nat. Rev. Neurosci. 13, 365-379. doi: 10.1038/nrn3170

Owald, D., Fouquet, W., Schmidt, M., Wichmann, C., Mertel, S., Depner, H., et al. (2010). A Syd-1 homologue regulates pre- and postsynaptic maturation in Drosophila. J. Cell Biol. 188, 565-579. doi: 10.1083/jcb.200908055 
Owald, D., Khorramshahi, O., Gupta, V. K., Banovic, D., Depner, H., Fouquet, W., et al. (2012). Cooperation of Syd-1 with neurexin synchronizes pre- with postsynaptic assembly. Nat. Neurosci. 15, 1219-1226. doi: 10.1038/nn.3183

Owald, D., and Sigrist, S. J. (2009). Assembling the presynaptic active zone. Curr. Opin. Neurobiol. 19, 311-318. doi: 10.1016/j.conb.2009.03.003

Patel, M. R., Lehrman, E. K., Poon, V. Y., Crump, J. G., Zhen, M., Bargmann, C. I., et al. (2006). Hierarchical assembly of presynaptic components in defined C. Elegans synapses. Nat. Neurosci. 9, 1488-1498. doi: 10.1038/nn1806

Patel, M. R., and Shen, K. (2009). RSY-1 is a local inhibitor of presynaptic assembly in C. Elegans. Science 323, 1500-1503. doi: 10.1126/science.1169025

Peled, E. S., Newman, Z. L., and Isacoff, E. Y. (2014). Evoked and spontaneous transmission favored by distinct sets of synapses. Curr. Biol.? 24, 484-493. doi: 10.1016/j.cub.2014.01.022

Petzoldt, A. G., Lu, J., and Sigrist, S. J. (2016). Science direct mechanisms controlling assembly and plasticity of presynaptic active zone scaffolds. Curr. Opin. Neurobiol. 39, 69-76. doi: 10.1016/j.conb.2016.04.009

Pulido, C., and Marty, A. (2017). Quantal fluctuations in central mammalian synapses: functional role of vesicular docking sites. Physiol. Rev. 97, 1403-1430. doi: 10.1152/physrev.00032.2016

Rasse, T. M., Fouquet, W., Schmid, A., Kittel, R. J., Mertel, S., Sigrist, C. B., et al. (2005). Glutamate receptor dynamics organizing synapse formation in vivo. Nat. Neurosci. 8, 898-905. doi: 10.1038/nn1484

Rebhun, L. I. (1956). Electron microscopy of basophilic structures of some invertebrate oocytes. I. Periodic lamellane and the nuclear envelope. J. Biophys. Biochem. Cytol. 2, 93-104. doi: 10.1083/jcb.2.1.93

Reddy-Alla, S., Böhme, M. A., Reynolds, E., Beis, C., Grasskamp, A. T., Mampell, M. M., et al. (2017). Stable positioning of Unc13 restricts synaptic vesicle fusion to defined release sites to promote synchronous neurotransmission. Neuron 95, 1350.e12-1364.e12. doi: 10.1016/j.neuron.2017.08.016

Regehr, W. G. (2012). Short-term presynaptic plasticity. Cold Spring Harb. Perspect. Biol. 4:a005702. doi: 10.1101/cshperspect.a005702

Rhee, J. S., Betz, A., Pyott, S., Reim, K., Varoqueaux, F., Augustin, I., et al. (2002). Beta phorbol ester- and diacylglycerol-induced augmentation of transmitter release is mediated by Munc13s and not by PKCs. Cell 108, 121-133. doi: 10.1016/S0092-8674(01)00635-3

Richmond, J. E., Weimer, R. M., and Jorgensen, E. M. (2001). an open form of syntaxin bypasses the requirement for UNC-13 in vesicle priming. Nature 412 , 338-341. doi: 10.1038/35085583

Ritzau-Jost, A., Delvendahl, I., Rings, A., Byczkowicz, N., Harada, H., Shigemoto, R., et al. (2014). Ultrafast action potentials mediate kilohertz signaling at a central synapse. Neuron 84, 152-163. doi: 10.1016/j.neuron.2014. 08.036

Rizo, J., and Südhof, T. C. (2012). The membrane fusion enigma: SNAREs, Sec1/Munc18 proteins, and their accomplices-guilty as charged? Annu. Rev. Cell Dev. Biol. 28, 279-308. doi: 10.1146/annurev-cellbio-101011-155818

Sakamoto, H., Ariyoshi, T., Kimpara, N., Sugao, K., Taiko, I., Takikawa, K., et al. (2018). Synaptic weight set by Munc13-1 supramolecular assemblies. Nat. Neurosci. 21, 41-49. doi: 10.1038/s41593-017-0041-9

Saviane, C., and Silver, R. A. (2006). Fast vesicle reloading and a large pool sustain high bandwidth transmission at a central synapse. Nature 439, 983-987. doi: 10.1038/nature04509

Scheiffele, P., Fan, J., Choih, J., Fetter, R., and Serafini, T. (2000). Neuroligin expressed in nonneuronal cells triggers presynaptic development in contacting axons. Cell 101, 657-669. doi: 10.1016/S0092-8674(00)80877-6

Scheuss, V., and Neher, E. (2001). estimating synaptic parameters from mean, variance, and covariance in trains of synaptic responses. Biophys. J. 81, 19701989. doi: 10.1016/S0006-3495(01)75848-1

Schmid, A., Hallermann, S., Kittel, R. J., Khorramshahi, O., Frölich, A. M., Quentin, C., et al. (2008). Activity-dependent site-specific changes of glutamate receptor composition in vivo. Nat. Neurosci. 11, 659-666. doi: 10.1038/nn.2122

Schmidt, H., Brachtendorf, S., Arendt, O., Hallermann, S., Ishiyama, S., Bornschein, G., et al. (2013). Nanodomain coupling at an excitatory cortical synapse. Curr. Biol. 23, 244-249. doi: 10.1016/J.CUB.2012.12.007

Schoch, S., Castillo, P. E., Jo, T., Mukherjee, K., Geppert, M., Wang, Y., et al. (2002). RIM1 $\alpha$ forms a protein scaffold for regulating neurotransmitter release at the active zone. Nature 415, 321-326. doi: 10.1038/415321a

Serra-Pagès, C., Kedersha, N. L., Fazikas, L., Medley, Q., Debant, A., and Streuli, M. (1995). The LAR transmembrane protein tyrosine phosphatase and a coiled-coil
LAR-interacting protein co-localize at focal adhesions. EMBO J. 14, 2827-2838. doi: 10.1002/j.1460-2075.1995.tb07282.x

Serra-Pagès, C., Medley, Q. G., Tang, M., Hart, A., and Streuli, M. (1998). Liprins, a family of LAR transmembrane protein-tyrosine phosphataseinteracting proteins. J. Biol. Chem. 273, 15611-15620. doi: 10.1074/JBC.273.25. 15611

Shin, H., Wyszynski, M., Huh, K. H., Valtschanoff, J. G., Lee, J. R., Ko, J., et al. (2003). Association of the kinesin motor KIF1A with the multimodular protein liprin-alpha. J. Biol. Chem. 278, 11393-11401. doi: 10.1074/jbc.M21187 4200

Shin, O. H., Lu, J., Rhee, J. S., Tomchick, D. R., Pang, Z. P., Wojcik, S. M., et al. (2010). Munc13 C2B domain is an activity-dependent $\mathrm{Ca}^{2+}$ regulator of synaptic exocytosis. Nat. Struct. Mol. Biol. 17, 280-288. doi: 10.1038/nsmb.1758

Siksou, L., Rostaing, P., Lechaire, J. P., Boudier, T., Ohtsuka, T., Fejtová, A., et al. (2007). Three-dimensional architecture of presynaptic terminal cytomatrix. J. Neurosci. 27, 6868-6877. doi: 10.1523/JNEUROSCI.1773-07.2007

Slater, C. R. (2015). The functional organization of motor nerve terminals. Prog. Neurobiol. 134, 55-103. doi: 10.1016/j.pneurobio.2015.09.004

Spinner, M. A., Walla, D. A., and Herman, T. G. (2017). Drosophila Syd-1 Has RhoGAP activity that is required for presynaptic clustering of Bruchpilot/ELKS but not neurexin-1. Genetics 208, 705-716. doi: 10.1534/genetics.117.300538

Stigloher, C., Zhan, H., Zhen, M., Richmond, J., and Bessereau, J. L. (2011). The presynaptic dense projection of the caenorhabditis elegans cholinergic neuromuscular junction localizes synaptic vesicles at the active zone through SYD-2/Liprin and UNC-10/RIM-dependent interactions. J. Neurosci. 31, 43884396. doi: 10.1523/JNEUROSCI.6164-10.2011

Südhof, T. C. (2012). The presynaptic active zone. Neuron 75, 11-25. doi: 10.1016/ j.neuron.2012.06.012

Sugie, A., Hakeda-Suzuki, S., Suzuki, E., Silies, M., Shimozono, M., Möhl, C., et al. (2015). Molecular remodeling of the presynaptic active zone of drosophila photoreceptors via activity-dependent feedback. Neuron 86, 711-725. doi: 10.1016/j.neuron.2015.03.046

Sylwestrak, E. L., and Ghosh, A. (2012). Elfn1 regulates target-specific release probability at CA1-interneuron synapses. Science 338, 536-540. doi: 10.1126/ science. 1222482

Takao-Rikitsu, E., Mochida, S., Inoue, E., Deguchi-Tawarada, M., Inoue, M., Ohtsuka, T., et al. (2004). Physical and functional interaction of the active zone proteins, CAST, RIM1, and Bassoon, in neurotransmitter release. J. Cell Biol. 164, 301-311. doi: 10.1083/jcb.200307101

Van Vactor, D. V., and Sigrist, S. J. (2017). ). Presynaptic morphogenesis, active zone organization and structural plasticity in Drosophila. Curr. Opin. Neurobiol. 43, 119-129. doi: 10.1016/J.CONB.2017.03.003

Varoqueaux, F., Sigler, A., Rhee, J. S., Brose, N., Enk, C., Reim, K., et al. (2002). Total arrest of spontaneous and evoked synaptic transmission but normal synaptogenesis in the absence of munc13-mediated vesicle priming. Proc. Natl. Acad. Sci. U.S.A. 99, 9037-9042. doi: 10.1073/pnas.122623799

Verhage, M., and Sørensen, J. B. (2008). Vesicle docking in regulated exocytosis. Traffic 9, 1414-1424. doi: 10.1111/j.1600-0854.2008.00759.x

Vyleta, N. P., and Jonas, P. (2014). Loose coupling between $\mathrm{Ca}^{2+}$ channels and release sensors at a plastic hippocampal synapse. Science 343, 665-670. doi: 10.1126/science. 1244811

Wadel, K., Neher, E., and Sakaba, T. (2007). The coupling between synaptic vesicles and $\mathrm{Ca}^{2+}$ channels determines fast neurotransmitter release. Neuron 53, 563-575. doi: 10.1016/j.neuron.2007.01.021

Wagh, D. A., Rasse, T. M., Asan, E., Hofbauer, A., Schwenkert, I., Dürrbeck, H., et al. (2006). Bruchpilot, a protein with homology to ELKS/CAST, is required for structural integrity and function of synaptic active zones in Drosophila. Neuron 49, 833-844. doi: 10.1016/j.neuron.2006.02.008

Walter, A. M., Haucke, V., and Sigrist, S. J. (2014). Neurotransmission: spontaneous and evoked release filing for divorce. Curr. Biol. 24, R192-R194. doi: 10.1016/j.cub.2014.01.037

Wang, L. Y., and Augustine, G. J. (2015). Presynaptic nanodomains: a tale of two synapses. Front. Cell. Neurosci. 8:455. doi: 10.3389/fncel.2014.00455

Wang, L. Y., Fedchyshyn, M. J., and Yang, Y. M. (2009). Action potential evoked transmitter release in central synapses: insights from the developing calyx of held. Mol. Brain 2:36. doi: 10.1186/1756-6606-2-36

Wang, L. Y., Neher, E., and Taschenberger, H. (2008). Synaptic vesicles in mature calyx of held synapses sense higher nanodomain calcium concentrations 
during action potential-evoked glutamate release. J. Neurosci. 28, 14450-14458. doi: 10.1523/JNEUROSCI.4245-08.2008

Wang, S. S. H., Held, R. G., Wong, M. Y., Liu, C., Karakhanyan, A., and Kaeser, P. S. (2016a). Fusion competent synaptic vesicles persist upon active zone disruption and loss of vesicle docking. Neuron 91, 777-791. doi: 10.1016/J.NEURON.2016. 07.005

Wang, T., Jones, R. T., Whippen, J. M., and Davis, G. W. (2016b). A2 $2-3$ is required for rapid transsynaptic homeostatic signaling. Cell Rep. 16, 2875-2888. doi: 10.1016/j.celrep.2016.08.030

Wang, Y., Liu, X., Biederer, T., and Südhof, T. C. (2002). A family of RIMbinding proteins regulated by alternative splicing: implications for the genesis of synaptic active zones. Proc. Natl. Acad. Sci. U.S.A. 99, 14464-14469. doi: 10.1073/pnas.182532999

Wang, Y., Sugita, S., and Sudhof, T. C. (2000). The RIM/NIM family of neuronal C2 domain proteins. Interactions with Rab3 and a new class of Src homology 3 domain proteins. J. Biol. Chem. 275, 20033-20044. doi: 10.1074/ jbc.M909008199

Weimer, R. M., Gracheva, E. O., Meyrignac, O., Miller, K. G., Richmond, J. E., and Bessereau, J. L. (2006). UNC-13 and UNC-10/Rim Localize synaptic vesicles to specific membrane domains. J. Neurosci. 26, 8040-8047. doi: 10.1523/ JNEUROSCI.2350-06.2006

Wichmann, C., and Moser, T. (2015). relating structure and function of inner hair cell ribbon synapses. Cell Tissue Res. 361, 95-114. doi: 10.1007/s00441-0142102-7

Wichmann, C., and Sigrist, S. J. (2010). The active zone T-bar - a plasticity module? J. Neurogenet. 24, 133-145. doi: 10.3109/01677063.2010.489626

Xuan, Z., Manning, L., Nelson, J., Richmond, J. E., Colón-Ramos, D. A., Shen, K., et al. (2017). Clarinet (CLA-1), a novel active zone protein required for synaptic vesicle clustering and release. eLife 6:e29276. doi: 10.7554/eLife.2 9276

Yang, Y. M., Fedchyshyn, M. J., Grande, G., Aitoubah, J., Tsang, C. W., Xie, H., et al. (2010). Septins regulate developmental switching from microdomain to nanodomain coupling of $\mathrm{Ca}^{2+}$ influx to neurotransmitter release at a central synapse. Neuron 67, 100-115. doi: 10.1016/j.neuron.2010.06.003

Zeng, X., Sun, M., Liu, L., Chen, F., Wei, L., and Xie, W. (2007). Neurexin-1 is required for synapse formation and larvae associative learning in Drosophila. FEBS Lett. 581, 2509-2516. doi: 10.1016/j.febslet.2007.04.068

Zhai, R. G., and Bellen, H. J. (2004). The architecture of the active zone in the presynaptic nerve terminal. Physiology 19, 262-270. doi: 10.1152/physiol.00014. 2004

Zhen, M., and Jin, Y. (1999). The liprin protein SYD-2 regulates the differentiation of presynaptic termini in C. Elegans. Nature 401, 371-375. doi: 10.1038/43886

Zhou, K., Stawicki, T. M., Goncharov, A., and Jin, Y. (2013). Position of UNC-13 in the active zone regulates synaptic vesicle release probability and release kinetics. eLife 2:e01180. doi: 10.7554/eLife.01180

Conflict of Interest Statement: The authors declare that the research was conducted in the absence of any commercial or financial relationships that could be construed as a potential conflict of interest.

Copyright (c) 2018 Ghelani and Sigrist. This is an open-access article distributed under the terms of the Creative Commons Attribution License (CC BY). The use, distribution or reproduction in other forums is permitted, provided the original author(s) and the copyright owner(s) are credited and that the original publication in this journal is cited, in accordance with accepted academic practice. No use, distribution or reproduction is permitted which does not comply with these terms. 